\title{
Surface Tension and Critical Point Measurements of Methane + Propane Mixtures
}

Kumarini N. SENEVIRATNE, Thomas J. HUGHES, Michael L. JOHNS, Kenneth N. MARSH ${ }^{\#}$, Eric F. MAY*

Fluid Science \& Resources Division, School of Mechanical \& Chemical Engineering, The University of Western Australia, Crawley WA 6009, Australia.

\# Deceased, $27^{\text {th }}$ July 2016

* Corresponding author: Eric.May@uwa.edu.au

\begin{abstract}
Surface tension predictions of hydrocarbon mixtures at vapor-liquid equilibrium are crucially important and used in the design of many unit operations in the production of liquefied natural gas (LNG). Predictive models for surface tension are not well tested for hydrocarbon mixtures at high pressures due to the limited data available at relevant conditions. A differential capillary rise apparatus consisting of a high-pressure sapphire equilibrium cell was constructed and used to measure the surface tension of methane + propane mixtures along three isotherms $T=(272.23$, 285.51 and 303.34) $\mathrm{K}$ at pressures up to $9 \mathrm{MPa}$. The capillary diameters were calibrated using pure saturated propane at $271 \mathrm{~K}$, and the technique was validated by measurements of pure ethane. The measured surface tensions were compared with the available data and the predictions of various models, including the Parachor method and Linear Gradient Theory: both were able to describe the data within their uncertainty. However, the default surface tension model for hydrocarbon mixtures implemented in the widely-used software package REFPROP 9.1 gave poor predictions; this was rectified through the implementation of the Parachor method in a beta-version of REFPROP 9.2. Critical points were also measured from observations of critical opalescence and the disappearance of the bulk interface. The measured mixture critical points were consistent with, and extended, literature values for this binary system. The measured critical points differed by between 0.5 and $+27 \mathrm{~K}$ from predictions made with the GERG-2008 equation of state (EOS) and between -5 and $+10 \mathrm{~K}$ for the Peng-Robinson EOS.
\end{abstract}

\section{Key Words}

Surface tension; critical points; hydrocarbons 


\section{Introduction}

Natural gas is a multicomponent mixture comprised principally of hydrocarbons. As part of the extraction and purification processes used to prepare this major energy source for safe transport and storage, it is often found as a mixture of vapour and liquid phases. The interaction of these phases is governed by the surface tension of the mixture. Surface (or interfacial) tension is due to the existence of imbalanced intermolecular forces at the liquid/vapour interface. Surface tension is a key thermodynamic property of central interest to the natural gas industry affecting, for example, multiphase flow, separation efficiencies of scrubber columns, the efficacy of heat transfer and the nucleation of new phases. ${ }^{1 ; 2 ; 3 ; 4}$ Natural gas production facilities operate across a wide range of temperature and pressures. The accurate prediction of surface tension for natural gas at these operating conditions can be difficult, especially when approaching the mixture's critical point.

Methods of predicting surface tension as a function of temperature, pressure and phase compositions are therefore essential to engineers designing and operating natural gas plants. Models for predicting surface tension are generally empirical and comprised of two components. The first component provides predictions of the phase compositions and densities based on vapour liquid equilibrium (VLE) calculations usually made with an equation of state (EOS). The second component then links the surface tension to the properties of the liquid and vapour phases, usually in an empirical way. The models used to predict surface tension for pure components are well tested and include the Parachor method ${ }^{5 ; 6}$ and variations of Guggenheim-Katayama equations ${ }^{7 ; 8}$ such as those by Mulero et al. ${ }^{3}$. The models available to predict surface tensions in mixtures include the Parachor model ${ }^{9}$, the critical-scaling model of Moldover and Rainwater ${ }^{10}$ and the Linear Gradient Theory ${ }^{11}$. These models for predicting mixture surface tensions are typically based on some method of combining the pure component surface tension values. Binary mixture data are used to test and validate the models for predicting the surface tension of mixtures. Validating and/or improving the accuracy of these predictive models thus requires high quality surface tension measurements of mixtures.

The methane (1) + propane (2) system is one of the most important binary mixtures for the description of natural gas systems. However, experimental surface tension values for binary mixtures of methane and propane are restricted to the work done by Weinaug and Katz ${ }^{9}$ and Haniff and Pearce ${ }^{12}$. Weinaug and Katz ${ }^{9}$ used the single capillary rise method to measure surface tension for methane and propane mixtures. These measurements were conducted isothermally at temperatures between $T=(258.15$ and 363.15$) \mathrm{K}$ starting with pure propane and by increasing the methane fraction over the range $p=(0.29$ to 8.48$) \mathrm{MPa}$ until the surface tension values were too low for accurate measurement. The work by Haniff and Pearce ${ }^{12}$ used laser-light scattering to determine the surface tension while approaching the critical temperature for one mixture $\left(z_{1}=0.62, z_{2}=0.38\right)$ across the range $T=(302.75$ to 312.35$) \mathrm{K}$. The phase compositions and densities for the surface tension calculation presented by Weinaug and Katz ${ }^{9}$ and Haniff and Pearce ${ }^{12}$ were derived from the phase equilibrium data of Sage et al. ${ }^{13}$. There has been substantial improvement since the work done by Sage et al. ${ }^{13}$, in the accuracy with which the phase compositions and densities of the methane + propane system can be described ${ }^{14}$. Thereby it should be possible to significantly improve upon the description of the system's surface tension as determined by these authors, and in addition, continue those surface tension measurements up to the critical point. 
Static surface tension measurements are typically classified into microbalance techniques, capillary pressure measurements, capillary and gravity forces equilibrium measurements and forced droplet distortion measurements. Microbalance techniques such as Wilhelmy plate ${ }^{7 ;}$, du Noüy Ring $^{16}$ and du Noüy-Padday $\operatorname{rod}^{17}$ are traditionally used for low pressure systems involving liquid-air interfaces and are not easily implemented for use in high pressure systems. Surface tension for high pressure and temperature systems can be measured using the pendant $\operatorname{drop}^{1 ; 18 ; 19 ; 20}$, sessile drop ${ }^{21}$, capillary rise $^{22 ; 23 ; 24 ; 25 ; 26 ; 27}$, laser light scattering ${ }^{12 ; 28 ; 29}$, spinning drop ${ }^{30}$ and drop weight volumes methods ${ }^{31 ;}$ 32. The advantages and disadvantages of these methods depend on the accuracy, sensitivity and range of surface tension measurements required. The drop volume and the laser light scattering methods are extremely sensitive to any vibrations around the system which can make obtaining reliable measurements difficult. ${ }^{12 ;} 32$ The pendant/sessile drop method and spinning drop method have limitations based on the Bond number (ratio of gravitational to surface tension forces over the length scale of the droplet). Accurate results for the standard pendant or sessile drop method are generally limited by Bond number $\left(B_{0}>0.2\right)$ and, typically, systems with lower surface tension values produce low Bond numbers and unstable drops. ${ }^{20 ;}{ }^{33}$ Variations to the typical pendant drop methodology can produce higher accuracy results at lower Bond numbers ${ }^{33}$. The spinning drop method can in principle deliver high accuracy measurements of low surface tensions but requires a large density difference between the phases and is still generally limited to measurements at high Bond numbers due to limitations in maximum rotational speed. ${ }^{34}$ The capillary rise method is welltested and capable of measuring a range of surface tension values limited only by the diameters of the capillaries, at high pressures and over a wide range of temperatures, with low sensitivity to vibrations. The differential capillary rise method ${ }^{35}$, in which two capillaries are used to determine the surface tension as used in this work eliminates the uncertainties associated with determination of the bulk liquid level. An additional benefit of the capillary rise method, which involves the use of a visual equilibrium cell, is that it facilitates determination of the mixture critical point through two independent methods: the estimation of the zero surface tension condition and the observation of critical opalescence.

This paper presents (i) an experimental setup and method that allows the measurement of surface tension up to the critical point, (ii) the calibration and validation of the setup with pure hydrocarbon fluids, (iii) surface tension and critical point data for methane and propane mixtures, and (iv) the comparison of the experimental data obtained with predictive models used by industry. The results obtained helped identify a significant problem with the implementation of a surface tension model in a widely-used software package, which has now been rectified. The critical point data collected can be compared to the EOS-predicted critical point and thereby test the performance of the EOS.

\section{Predictive Models}

The development of Guggenheim-Katayama equations ${ }^{7 ;} 8$ by Mulero et al. ${ }^{3}$, to describe pure component surface tensions correlates them as a function of reduced temperature.

$$
\gamma(T)=\sum_{j=0}^{k-1} \sigma_{j}\left(1-\frac{T}{T_{c}}\right)^{m_{j}}
$$

Here $\gamma$ is the surface tension, $T$ is the temperature of the fluid, $T_{\mathrm{c}}$ is the critical temperature of the fluid, $\sigma_{\mathrm{j}}$ and $\mathrm{m}_{\mathrm{j}}$ are parameters fitted to measured surface tensions data and $k$ is the number of 
terms which is dependent on the fluid. Such correlations are the default models for pure fluids implemented in the software packages REFPROP $9.1^{36}$ and the $\beta$-version of REFPROP 9.2, which has not yet been widely released but was developed partly in response to the experimental data reported here.

Moldover and Rainwater ${ }^{10}$ developed a method for predicting surface tension based on two scale factor universality and knowledge of the fluid's Helmholtz free energy. The two scale factor universality states that fluids when scaled appropriately can be described by a fluid independent function when close to the critical point, and that when in the two phase region, there is a universal relationship between surface tension, Helmholtz free energy and correlation length. This approach was used successfully to predict the surface tension of pure fluids and binary mixtures of carbon dioxide and $n$-butane by Moldover and Rainwater ${ }^{10}$. A modified implementation of this predictive model for mixtures is the default property package used for calculating the surface tension of hydrocarbons mixtures in REFPROP 9.1. Unfortunately, no details regarding the modifications to the original model of Moldover and Rainwater as implemented within REFPROP 9.1 are available ${ }^{37}$.

The Parachor method can be applied to calculate the surface tension of both single-component fluids and mixtures. This method is based on the observation that the ratio between the quartic root of the surface tension and difference in the phase densities is approximately constant and characteristic of the pure fluid. This characteristic constant is known as the Parachor, $\wp$, and it can be estimated from the chemical structure of the pure component ${ }^{38}$ although it is usually determined experimentally from surface tension data for pure fluids:

$$
\wp=\frac{\gamma^{1 / n}}{\rho_{l}-\rho_{v}}
$$

Here $\rho_{\mathrm{I}}$ and $\rho_{\mathrm{v}}$ are the densities of the liquid and vapour phases, respectively, and $n$ is a constant approximately equal to four, but often in practice is treated as an adjustable parameter to improve the representation of experimental data. For example, $n=4$ in the implementation of the Parachor method within the software package Multiflash $4.4^{39}$, while $n=3.87$ in the implementation within REFPROP $9.2(\beta)^{40}$.

For predicting mixture surface tensions, $\gamma_{\text {mix }}$, the Parachor values of each component are combined as follows ${ }^{9 ; 41 ; 42}$ :

$$
\gamma_{\text {mix }}=\left(\rho_{l} \sum x_{i} \wp_{i}-\rho_{v} \sum y_{i} \wp_{i}\right)^{n}
$$

where $x_{i}$ and $y_{i}$ are the liquid and vapour mole fractions of component $i$, respectively, and the phase densities refer to the liquid and vapour mixtures with those compositions. Table 1 lists values of the Parachors used for the components in this work as implemented in the two software packages, and as calculated for each molecule by Negi and Anand ${ }^{38}$

Table 1: Parachor values used in Multiflash and REFPROP $9.2(\beta)$ for calculation of surface tension

\begin{tabular}{|c|c|c|c|}
\hline Component & $\begin{array}{c}\text { REFPROP 9.2(ß)/ } \\
\left(\mathrm{mN} \cdot \mathrm{m}^{-1}\right)^{1 / 3.87} \cdot \mathrm{m}^{3} \cdot \mathrm{kg}^{-1}\end{array}$ & $\begin{array}{c}\text { Multiflash 4.4/ } \\
\left(\left(\mathrm{mN} \cdot \mathrm{m}^{-1}\right)^{1 / 4} \cdot \mathrm{m}^{3} \cdot \mathrm{kg}^{-1}\right.\end{array}$ & $\begin{array}{c}\text { Negi and Anand } \\
\left(\left(\mathrm{mN} \cdot \mathrm{m}^{-1}\right)^{1 / 4} \cdot \mathrm{m}^{3} \cdot \mathrm{kg}^{-1}\right.\end{array}$ \\
\hline Methane & 75.17 & 72.60 & 73.20 \\
\hline Propane & 154.72 & 150.8 & 151.2 \\
\hline
\end{tabular}


Central to any implementation of the Parachor method is the means by which densities are estimated. In the Multiflash 4.4 implementation, there are two options: Macleod Sugden (MCS) and Macleod Sugden Advanced (MCSA). Both allow the user to specify various equations of state (EOS) for estimating the liquid phase density; however MCS simply treats the vapour phase as an ideal gas $^{39}$. In this work we used the MCSA option, together with the GERG-2008 EOS as implemented in Multiflash 4.4. For the Parachor method implemented in REFPROP 9.2( $\beta$ ), the GERG-2008 EOS was also used.

A more recent model for surface tension predictions is the Linear Gradient Theory (LGT) ${ }^{11}$. This draws upon the framework of the more general Gradient Theory, ${ }^{11 ;}{ }^{43}$ which estimates surface tensions from calculation of the Helmholtz energy density of the single phase fluids and an influence parameter used to describe the two-phase system. Further detail is provided by Stenby and coworkers $^{11}$. An implementation of the LGT is provided within the property package Multiflash 4.4, in which the Peng Robinson Advanced (PR-A) cubic EOS is used to estimate vapour and liquid phase compositions and densities; no option is provided within the software package for using the GERG 2008 EOS with the Linear Gradient Theory (LGT) surface tension model.

\section{Experimental Surface Tension Determination by Capillary Rise}

The capillary rise method allows the calculation of surface tension based on equations developed from a force balance across the liquid meniscus ${ }^{44}$. The differential capillary rise method is a modification of the single capillary rise method and requires calculation of the capillary constant, $a^{2}$ :

$$
a^{2}=\frac{\left(h_{i}-h_{j}\right)}{\left(1 / b_{i}-1 / b_{j}\right)}
$$

where the radii of the menisci for the smaller and larger capillary are represented by $b_{i}$ and $b_{j}$, respectively, and the liquid height rise from the bulk liquid to each meniscus inside these capillaries are $h_{i}$ and $h_{j}$, respectively. The radius of a meniscus can be calculated from:

$$
\frac{r_{i}}{b_{i}}=\cos \theta
$$

where $r_{i}$ is the radius of the capillary, and $\theta$ is the contact angle between the liquid meniscus and the solid capillary wall ${ }^{44}$.

The contact angle is a measure of the wettability of the solid (glass) surface by the liquid. While it is not possible to determine the contact angle of a fluid inside a glass capillary from simple visual observations when the fluid has a lower refractive index than the glass, there is a strong physical argument that zero contact angle will be the rule for measurements near the fluid's critical point ${ }^{45}$. However, the radius of the meniscus can be approximated through equations from Lane ${ }^{46}$ based on work by Sugden ${ }^{35}$ and Rayleigh ${ }^{44}$. For this work, it was found that implementation of the Lane equations produced a maximum shift of $0.032 \mathrm{mN} / \mathrm{m}$ relative to surface tensions calculated based on the assumption that $b_{i}=r_{i}$ when $\theta=0$. If this assumption is removed and the Lane equations are used to determine a radius of the meniscus that differs from the capillary radius, the resulting contact angles were small, with an average of $7^{\circ}$ and a maximum of $16^{\circ}$; this latter value was obtained for one of the lowest surface tensions measured, and might thus be inflated due to 
numerical error in the solution of the required non-linear equation. Low contact angles are also consistent with the literature for hydrocarbons on borosilicate glass; in this work the glass capillaries were routinely washed through with chromic acid to remove grease, which was found to be important for obtaining reliable values ${ }^{47}$. The impact of using the Lane equations was negligible in comparison with other experimental uncertainties and, thus, in this work the contact angle was always assumed to be zero.

Surface tension, $\gamma$, was calculated from the capillary constant by:

$$
\gamma=\frac{1}{2} g a^{2}\left(\rho_{l}-\rho_{v}\right)
$$

where $\mathrm{g}=9.81 \mathrm{~m} / \mathrm{s}^{2}$. In this work the GERG-2008 $\operatorname{EOS~}^{48 ; 49}$ was used to calculate the liquid, $\rho_{l}$ and vapour density, $\rho_{v}$ from the measured temperature, pressure and overall composition of the two phase system. The overall composition was determined by the volumetric method as discussed below.

\section{Method}

\section{a. Apparatus and Materials}

The component pure fluids used in these experiments and their manufacturer quoted minimum purities are listed in Table 2. No further purification or analysis of the composition of these substances was performed.

Table 2: Chemical source and quoted minimum purity. No further chemical analysis or purification was performed.

\begin{tabular}{ccc} 
Chemical & Source & Manufacturer's Purity in Mole Fractions \\
\hline Ethane & Coregas & 0.99990 \\
Methane & Coregas & 0.99995 \\
Nitrogen & Coregas & 0.99999 \\
Propane & Coregas & 0.99990
\end{tabular}

A high pressure sapphire cell was made from a sapphire cylinder purchased from Rayotek Scientific Inc. ${ }^{50}$ and had a $57.22 \mathrm{~mm}$ outer diameter, a wall thickness of $9.46 \mathrm{~mm}$, and a length of $100.1 \mathrm{~mm}$. The base plates and flanges were made from Nitronic 50HS Steel. The cell housed a Polyether Ether Ketone (PEEK) capillary holder that could accommodate six capillaries. These borosilicate glass capillaries were purchased from Friedrich and Dimmock Inc. ${ }^{51}$. Three sizes of capillaries were used: each had an inner radius specified by the manufacturer of $r_{1}=0.2540 \mathrm{~mm}, r_{2}=0.1395 \mathrm{~mm}$ and $r_{3}=$ $0.1015 \mathrm{~mm}$ with a $10 \%$ tolerance. Prior to use the capillaries were cleaned with chromic acid and dried with dry nitrogen to remove any contamination. After each set of surface tension measurements along a given isotherm, the cell was vented and dis-assembled. At this point the capillaries were washed thoroughly with acetone and dried with dry nitrogen. Precise values of the capillary inner radii were determined by calibration using reference values for the surface tension of pure propane as discussed in detail in Section 5. The experimental setup is shown in Figure 1. 

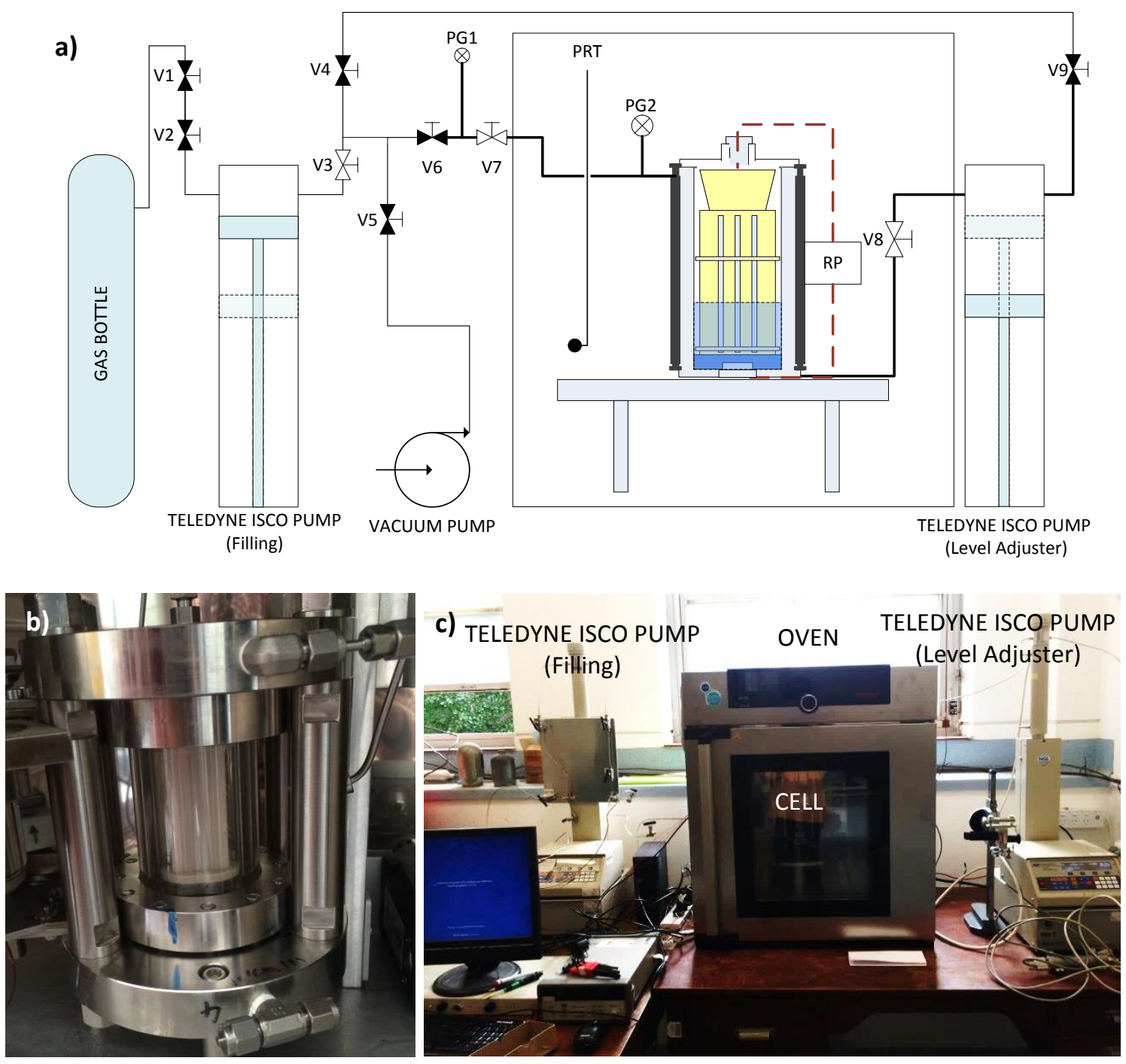

Figure 1: Schematic showing surface tension cell and a recirculation pump (RP) for mixing. The liquid level was controlled by two syringe pumps (ISCO) and valves attached to the cell. The temperature

was controlled by a stirred liquid or air bath. The acronyms PRT and PG refer to a Platinum

Resistance Thermometer and Pressure Gauge, respectively. PG1 represents the Paroscientific pressure transducer used for estimating the amount of methane injected into the cell and PG2 is the Omega PX-409 used for measuring pressure in the cell, b) photograph surface tension cell with capillaries held within a Teflon capillary holder, and c) picture of cell inside the Memmert oven.

Temperature control of the sapphire cell containing the capillaries was achieved with two different systems:

1) A liquid bath, with a clear pyrex window, filled with a mixture of ethylene glycol and water that operated over a temperature range from (271.15 to 303.15) K. The temperature of the liquid bath was set and maintained using a cooling coil connected to a refrigeration unit.

2) A Memmert Oven UN110 (air bath) with a four layer glass window to allow visualisation and an operating temperature range from (293.15 to 523.15$) \mathrm{K}$.

Lighting of the cell and the internal capillaries was achieved by a Aquopro $12 \mathrm{~V}$ white LED pond light that was either submerged inside the liquid bath or held in the oven. The temperature within both systems was monitored with a Platinum Resistance Thermometer (PRT), with an uncertainty of 0.08 
$\mathrm{K}$ across a range from (245.15 to 392.15$) \mathrm{K}$. The pressure inside the cell was measured using an Omega PX-409 5V transducer with an uncertainty of $0.036 \%$ of the reading over the pressure range 0 to $13 \mathrm{MPa}$. The Omega PX-409 was calibrated using a Paroscientific Digiquartz ${ }^{\circledR}$ pressure transmitter (Series $9000-2 \mathrm{~K}-101$ ) with a relative uncertainty of $0.01 \%$ over the pressure range of 0 to $13.79 \mathrm{MPa}$. The Paroscientific Digiquartz ${ }^{\circledR}$ pressure transmitter (Series 9000-2K-101) also provided measures of the ambient temperature and the pressure in the filling syringe pump, which was needed for determining the composition using the volumetric method, discussed below. The temperature measurement from the Paroscientific Digiquartz ${ }^{\circledR}$ pressure transmitter was calibrated using the PRT.

\section{b. Procedure}

Prior to loading, the cell and all the associated lines were evacuated using a Varian DS102 Vacuum Pump. Once the temperature of the cell stabilised, liquid propane (or ethane for the pure fluid calibrations) was added into the cell using the filling syringe pump, operated at a constant flow rate. Fluid was injected until the liquid level covered one third the length of the capillaries. Valve V8 remained open for the duration of the experiment. The binary mixture in this work was produced insitu by injecting a known amount of methane from the filling syringe pump into the surface tension cell. Once methane was added into the system V6 was closed.

The overall mole fraction composition of the methane (1) + propane (2) mixture in the cell was estimated using the volumetric method by keeping track of the cumulative amounts of each component injected. The change in the amount of component $j$ in the cell, $\Delta n^{(j)}$, was calculated based on the syringe pump volumes measured before and after injection, combined with the measured pressures and (ambient) temperature of the syringe pump before and after the injection.

$$
\Delta n^{(j)}=\rho_{i}^{(j)} V_{i}-\rho_{f}^{(j)} V_{f}
$$

Here $\rho$ is the molar density calculated using the reference EOS for propane ${ }^{52}$, methane ${ }^{53}$ or ethane ${ }^{54}$ (for the validation measurements) from the measured pressure, $p$, and temperature, $T ; V$ is the volume of the syringe pump. The subscripts $i$ and $f$ denote the values measured before and after an injection. The overall methane mole fraction in the binary mixture was then calculated via:

$$
z_{1}=\frac{\sum \Delta n^{(1)}}{n^{(2)}+\sum \Delta n^{(1)}}
$$

Here $n^{(2)}=\Delta n^{(2)}$ since propane was injected into the evacuated cell only once and the summations are over each methane injection made for a given isothermal measurement until the critical point was reached.

After methane was added it was necessary to lower the bulk interface below the bottom of the capillaries prior to operating the recirculation pump (RP) to ensure the system was properly mixed, as any liquid trapped within the capillaries would not readily equilibrate with the vapour phase. The level-adjusting syringe pump connected to the base of the cell was used to lower the bulk liquid level at $0.1 \mathrm{ml} / \mathrm{min}$, while the filling syringe pump connected to the top of cell was used to keep the mixture at constant pressure. Once the bulk interface had reached a sufficiently low level, an hour was allowed for the capillaries to drain and the capillary bores were monitored visually for any liquid entrapment. The recirculation pump was then activated using either a pneumatically driven shaft 
(liquid bath) or a shaft driven by a stepper motor (air bath), running at one recirculation cycle every 2 seconds and displacing approximately $0.1 \mathrm{ml} /$ cycle. A minimum of 30 minutes of mixing time was allowed to ensure the system reached equilibrium. Once the mixing was completed the bulk liquid level was returned to a position above the base of the capillaries by injecting with the level-adjusting syringe pump in constant flow mode, and withdrawing the filling syringe pump in constant pressure mode. This process of moving the bulk liquid level and mixing was repeated twice to ensure the cell was thoroughly equilibrated. The liquid remaining in the lines below the cell is not well mixed and this dead volume was assumed to contain pure propane, which was accounted for in the calculation of the overall composition; as discussed below the uncertainty associated with this assumption constituted the largest uncertainty in the determination of the overall composition. After repositioning the bulk interface so that the surface tension measurement could be completed, the heights of the liquid in each capillary were recorded relative to the bulk level 5 times over 30 minutes to ensure no changes were occurring and that the system was at equilibrium. The system's pressure and methane mole fraction were then increased using the filling syringe pump and these steps were repeated. Completion of an isothermal measurement was achieved once the bulk interface disappeared and critical opalescence observed, as described further below.

The component uncertainties contributing to the standard uncertainty for each addition of methane and propane from the pressure, temperature and volume change measurements, as well as from the unmixed volume are summarised in Table 3. These were combined using Equation 9 to give a standard uncertainty in $\Delta n^{(1)}$ of $4.5 \times 10^{-5} \mathrm{~mol}$ and $\Delta n^{(2)}$ of $5.05 \times 10^{-3} \mathrm{~mol}$. This latter quantity is dominated by the uncertainty associated with the number of moles of propane in the un-mixed volume outside the cell, which can vary with time due to diffusion and thermo-diffusion ${ }^{55}$ when the interface is static, and potentially by advective mixing when the interface was moved up or down. The former effects were mitigated by the fact that the time constant associated with diffusion on the length scale between the vapour-liquid interface and the dead volume was about 6 times longer than the measurement time. The latter effect was mitigated by only moving the interface very slowly, at $0.5 \mathrm{~mL} / \mathrm{min}$ or $0.1 \mathrm{~mL} / \mathrm{min}$ when the interface was within $1 \mathrm{~mL}$ of the bottom of the capillaries. We estimated the uncertainty in the amount of propane remaining in the dead volume over the course of the experiment to be a maximum of $10 \%$ of the dead volume. The uncertainty in the mixture's composition is initially equal to the uncertainty of the amount of propane in the cell and accumulates with each addition of methane. The uncertainties in composition are shown for each individual mixture in Table 8 based on the uncertainties of methane and propane injection.

$$
u\left(\Delta n^{(j)}\right)=\sqrt{\left(\frac{\partial \Delta n^{(j)}}{\partial p} u(p)\right)^{2}+\left(\frac{\partial \Delta n^{(j)}}{\partial T} u(T)\right)^{2}+\left(\frac{\partial \Delta n^{(j)}}{\partial V} u(V)\right)^{2}+\left(\frac{\partial \Delta n^{(j)}}{\partial V_{d}} u\left(V_{d}\right)\right)^{2}}
$$

Table 3: Standard uncertainties associated with the determination of the amount of methane added into the cell at each interval and the amount of propane added into the cell at the start of each isotherm

\begin{tabular}{|l|c|c|c|}
\hline Source & Uncertainty & $\begin{array}{c}\text { Contribution to } \\
\boldsymbol{u}\left(\boldsymbol{\Delta} \boldsymbol{n}^{(\mathbf{1})}\right) / \mathrm{mol}\end{array}$ & $\begin{array}{c}\text { Contribution to } \\
\boldsymbol{u}\left(\boldsymbol{\Delta} \boldsymbol{n}^{(\mathbf{2})}\right) / \mathbf{m o l}\end{array}$ \\
\hline Temperature Measurement & $0.08 \mathrm{~K}$ & $3.80 \times 10^{-5}$ & $3.13 \times 10^{-5}$ \\
\hline Pressure Measurement & $1.38 \mathrm{kPa}$ & $1.88 \times 10^{-5}$ & $8.79 \times 10^{-6}$ \\
\hline Syringe Pump Volume Measurement & $0.01 \mathrm{~cm}^{3}$ & $1.38 \times 10^{-5}$ & $1.05 \times 10^{-5}$ \\
\hline Unmixed propane & $0.5 \mathrm{~cm}^{3}$ & ---- & $5.05 \times 10^{-3}$ \\
\hline Total & & $4.46 \times 10^{-5}$ & $5.05 \times 10^{-3}$ \\
\hline
\end{tabular}


The mole fraction of methane in the liquid phase, $x_{1}$, was estimated via a flash calculation using the GERG-2008 EOS as implemented in REFPROP, from the measured temperature, pressure and overall mixture composition. For binary mixtures of methane + propane, May et al. ${ }^{14}$ showed recently that the root mean squared (r.m.s.) deviation between liquid phase methane mole fraction measured over the temperature range from (203 to 283) $\mathrm{K}$ at pressures to $8 \mathrm{MPa}$ and those calculated with the GERG-2008 EOS was 0.0087 . When combined with $u\left(z_{1}\right)$, the standard uncertainty in the liquid phase methane mole fraction calculated from the overall composition and the flash calculation was estimated to be 0.0092 . The uncertainty in liquid phase methane mole fraction did not significantly change as methane was added.

The uncertainty of the surface tension measurement depends on the accuracy of the height measurements, the calibration of the capillary radii and the accuracy of the phase densities calculated with the GERG-2008 EOS. The dominant contribution to the uncertainty of the surface tension measurement was the uncertainties associated with the liquid height measurement. The relative uncertainty of the capillary radii determined by calibration was estimated to be less than $1.4 \%$ based on the stated uncertainty of the reference surface tension value for propane and the uncertainty of the height measurements performed during the calibration experiment. The uncertainty in the phase densities calculated using the GERG-2008 EOS ${ }^{48 ; 4}$ was estimated to be $0.1 \%$ for these mixtures based on the quoted EOS uncertainty (although we note that recent density measurements of this system ${ }^{53}$ suggest that the claimed EOS uncertainty may be optimistic).

$$
u(\gamma)=\sqrt{\left(\frac{\partial \gamma}{\partial h} u(h)\right)^{2}+\left(\frac{\partial \gamma}{\partial r} u(r)\right)^{2}+\left(\frac{\partial \gamma}{\partial \rho} u(\rho)\right)^{2}}
$$

The combined standard uncertainty in the measured surface tension was then estimated using Equation 11 from the component uncertainties in the measurement of surface tension, temperature and pressure. The measured temperature and pressure were required for calculating the phase densities required for calculating surface tension. The combined standard uncertainty in the surface tension measurement is shown in Table 4.

$$
u_{c}(\gamma)=\sqrt{u(\gamma)^{2}+\left(\frac{\partial \gamma}{\partial T} u(T)\right)^{2}+\left(\frac{\partial \gamma}{\partial p} u(p)\right)^{2}}
$$

Table 4: Uncertainties associated with the measurement of surface tension.

\begin{tabular}{|l|c|c|c|}
\hline \multicolumn{1}{|c|}{ Source } & Uncertainty & $\begin{array}{c}\text { Contribution to } \\
\boldsymbol{u}(\gamma) / \mathrm{mN} \cdot \mathbf{m}^{-1}\end{array}$ & $\begin{array}{c}\text { Contribution to } \\
\boldsymbol{u}_{\mathrm{c}}(\gamma) / \mathbf{m N} \cdot \mathbf{m}^{-\mathbf{1}}\end{array}$ \\
\cline { 1 - 3 } Liquid Height Rise Measurement & $0.13 \mathrm{~mm}$ & 0.302 & \multirow{2}{*}{0.34} \\
\hline Radii Calibration & $0.004 \mathrm{~mm}$ & 0.15 & \\
\hline Density Estimation & $0.536 \mathrm{kgm}$ & 0.3 & 0.0014 \\
\hline Temperature Measurement & $0.08 \mathrm{~K}$ & --- & 0.00033 \\
\hline Pressure Measurement & $3.03 \mathrm{kPa}$ & --- & $\mathbf{0 . 3 4}$ \\
\hline Total & ---- & 0.34 & \\
\hline
\end{tabular}

The critical point was determined using two independent methods: the visualisation of critical opalescence and estimation of the zero surface tension condition by extrapolation of the measured trend. After the last surface tension measurement was completed, methane was added at 0.1 
$\mathrm{ml} / \mathrm{min}$ to the cell until the bulk liquid interface disappeared inside the sapphire cell. The recirculation pump was then used continuously post injection, and the contents of the sapphire cell were video recorded using a Cannon 7D camera with a Canon EF-S 15-85mm lens to detect the occurrence of critical opalescence. The critical opalescence measurement uncertainty in $z_{1}$, pressure, $p$, are tabulated in Table 9. In addition, the measured surface tension data were regressed to a third order polynomial and the root of this polynomial was then calculated to provide an independent estimate of the critical point. The uncertainty of the zero surface tension condition estimate was dependent on the quality of the polynomial fit and was individually calculated for each system. The critical parameters and uncertainties determined from the extrapolation method are summarised in the Supporting Information.

\section{Calibration and Validation with Pure Fluids}

The radius of each capillary was determined through calibration with a reference fluid, propane, using the single capillary rise method and surface tension value predicted from the correlation of Mulero et al. $^{3}$. Calibration for an individual capillary was completed by solving the single capillary rise equation for the radius ${ }^{56}, r_{i}$, assuming the contact angle, $\theta$, to be zero:

$$
r_{i}=\frac{2 \gamma}{h_{i} g\left(\rho_{l}-\rho_{v}\right)}
$$

The liquid and vapour densities, were calculated using the reference equation of state for propane by Lemmon et al. ${ }^{52}$. The capillary radius calibrations were conducted at $T=270.51 \mathrm{~K}$, the lowest temperature accessed in this work, using pure propane, because this gave the highest surface tension value and allowed the best resolution in the determination of each capillary's radius. The calibrated capillary radii were $r_{1}=(0.2811 \pm 0.0039) \mathrm{mm}$ and $r_{2}=(0.1555 \pm 0.0020) \mathrm{mm}$, which deviated by $0.0016 \mathrm{~mm}$ and $0.0017 \mathrm{~mm}$, respectively, from the manufacturer's nominal values. The radii calculated from the propane calibration at $T=270.51 \mathrm{~K}$ were used for all subsequent differential capillary rise surface tension determinations with both pure fluids and mixtures.

Thermal contraction (or expansion) of these borosilicate glass capillaries has a limited impact on surface tension measurement by the differential capillary rise method as it is the difference of the capillary radii that is required (see Equations 4 and 6). Based on a thermal expansion coefficient of $3.3 \times 10^{-6} \mathrm{~K}^{-1}$ for borosilicate glass ${ }^{57}$, the difference in radii would vary by $1.8 \times 10^{-5} \mathrm{~mm}$ in the temperature range from ( 270 to 315$) \mathrm{K}$. This is significantly lower than the uncertainty in the measurement for each individual capillary radius and thereby has been excluded as a source of uncertainty.

To validate the experimental technique, measurements were then conducted with pure propane at higher temperatures up to $314 \mathrm{~K}$, and then ethane up to its critical point of $303 \mathrm{~K}$. The results of the surface tension and vapour pressure measurements are listed in Tables 5 and 6 , and are shown in Figures 2 and 3, for propane and ethane, respectively. Also shown are corresponding values for vapour pressure and surface tension calculated using the reference EOS (Lemmon et al. ${ }^{52}$, Bücker and Wagner ${ }^{54}$ ) and the correlations of Mulero et al. ${ }^{3}$ for each component. The r.m.s deviation for the measured compared to reference EOS vapour pressure for ethane was $9.5 \times 10^{-4} \mathrm{MPa}$ and for propane was $2.9 \times 10^{-4} \mathrm{MPa}$. This deviation in vapour pressure is well within the expected uncertainty of pressure combined with the impact of uncertainty in measured temperature. The 
measured vapour pressures for ethane and propane are compared with literature sources in the Supporting Information Figures 1-4.

In all cases the agreement is excellent and within the estimated experimental uncertainty. Also shown are surface tensions predicted using the MCSA and LGT correlations implemented in Multiflash, ${ }^{39}$ which essentially also agree with the measurements within experimental uncertainty, although values of ethane's surface tension calculated using the MCSA model deviate from those calculated with the correlation of Mulero et al. by up to $0.27 \mathrm{mN} \cdot \mathrm{m}^{-1}$.

Table 5: Experimental Values Of Surface Tension, $\gamma$, and Vapour Pressure, $p$, Obtained for Pure Propane and compared with reference values $p_{\text {EOS }}$ and $\gamma_{\text {ref }}$ from the equation of state of Lemmon et al. ${ }^{52}$ and the correlation of Mulero et al. ${ }^{3 \text { a }}$

\begin{tabular}{|c|c|c|c|c|}
\hline $\boldsymbol{T} / \mathrm{K}$ & $\boldsymbol{p} / \mathrm{MPa}$ & $\left(\boldsymbol{p}-\boldsymbol{p}_{\text {EOS }}\right) / \mathrm{MPa}$ & $\gamma / \mathbf{~ m N . m ^ { - 1 }}$ & $\left(\gamma-\gamma_{\text {ref }}\right) / \mathbf{m N}^{-\mathbf{m}^{-1}}$ \\
\hline 270.51 & 0.4375 & $1.58 \times 10^{-4}$ & 10.40 & -0.07 \\
280.13 & 0.5837 & $-1.80 \times 10^{-4}$ & 9.28 & 0.03 \\
287.35 & 0.7154 & $-2.68 \times 10^{-4}$ & 8.37 & 0.03 \\
289.65 & 0.7621 & $1.85 \times 10^{-4}$ & 8.09 & 0.03 \\
291.75 & 0.8062 & $1.73 \times 10^{-4}$ & 7.78 & -0.02 \\
297.98 & 0.9482 & $2.38 \times 10^{-4}$ & 7.12 & 0.07 \\
300.92 & 1.0212 & $2.50 \times 10^{-4}$ & 6.57 & -0.12 \\
314.06 & 1.3980 & $-5.03 \times 10^{-4}$ & 4.99 & -0.17 \\
\hline
\end{tabular}

${ }^{a}$ Standard uncertainties in temperature $u(T)=0.08 \mathrm{~K}, u(p) / p=0.036 \%, u(\gamma)=0.34 \mathrm{mN} \cdot \mathrm{m}^{-1}$.

Table 6: Experimental Values Of Surface Tension, $\gamma$, and Vapour Pressure, $p$, Obtained for Pure Ethane and compared with reference values $p_{\text {EOS }}$ and $\gamma_{\text {ref }}$ from the equation of state of Bücker and Wagner ${ }^{54}$ and the correlation of Mulero et al. ${ }^{3}$

\begin{tabular}{|c|c|c|c|c|}
\hline $\boldsymbol{T} / \mathrm{K}$ & $\boldsymbol{p} / \mathrm{MPa}$ & $\left(\boldsymbol{p}-\boldsymbol{p}_{\text {EOS }}\right) / \mathrm{MPa}$ & $\gamma / \mathbf{m N} \cdot \mathbf{m}^{-1}$ & $\left(\gamma-\gamma_{\text {ref }}\right) / \mathbf{m N} \cdot \mathbf{m}^{-1}$ \\
\hline 274.62 & 2.4725 & $-1.44 \times 10^{-4}$ & 2.95 & -0.09 \\
279.17 & 2.7532 & $6.10 \times 10^{-5}$ & 2.40 & -0.09 \\
283.79 & 3.0609 & $-7.97 \times 10^{-4}$ & 1.85 & -0.10 \\
291.25 & 3.6152 & $1.84 \times 10^{-3}$ & 1.05 & -0.09 \\
293.15 & 3.7643 & $-1.17 \times 10^{-3}$ & 0.95 & 0.10 \\
294.16 & 3.8480 & $-3.57 \times 10^{-4}$ & 0.91 & -0.04 \\
295.04 & 3.9199 & $-1.44 \times 10^{-3}$ & 0.81 & 0.04 \\
297.18 & 4.1055 & $7.59 \times 10^{-4}$ & 0.62 & 0.05 \\
299.13 & 4.2775 & $-1.10 \times 10^{-4}$ & 0.43 & 0.02 \\
301.25 & 4.4719 & $-1.38 \times 10^{-3}$ & 0.27 & 0.04 \\
303.10 & 4.6503 & $1.07 \times 10^{-4}$ & 0.13 & 0.02 \\
304.95 & 4.8325 & $-1.64 \times 10^{-3}$ & 0.02 & 0.01 \\
dard uncertainties in temperature $u(T)=0.08 \mathrm{~K}, u(p) / p=0.036 \%, u(\gamma)=0.34 \mathrm{mN} \cdot \mathrm{m}^{-1}$.
\end{tabular}




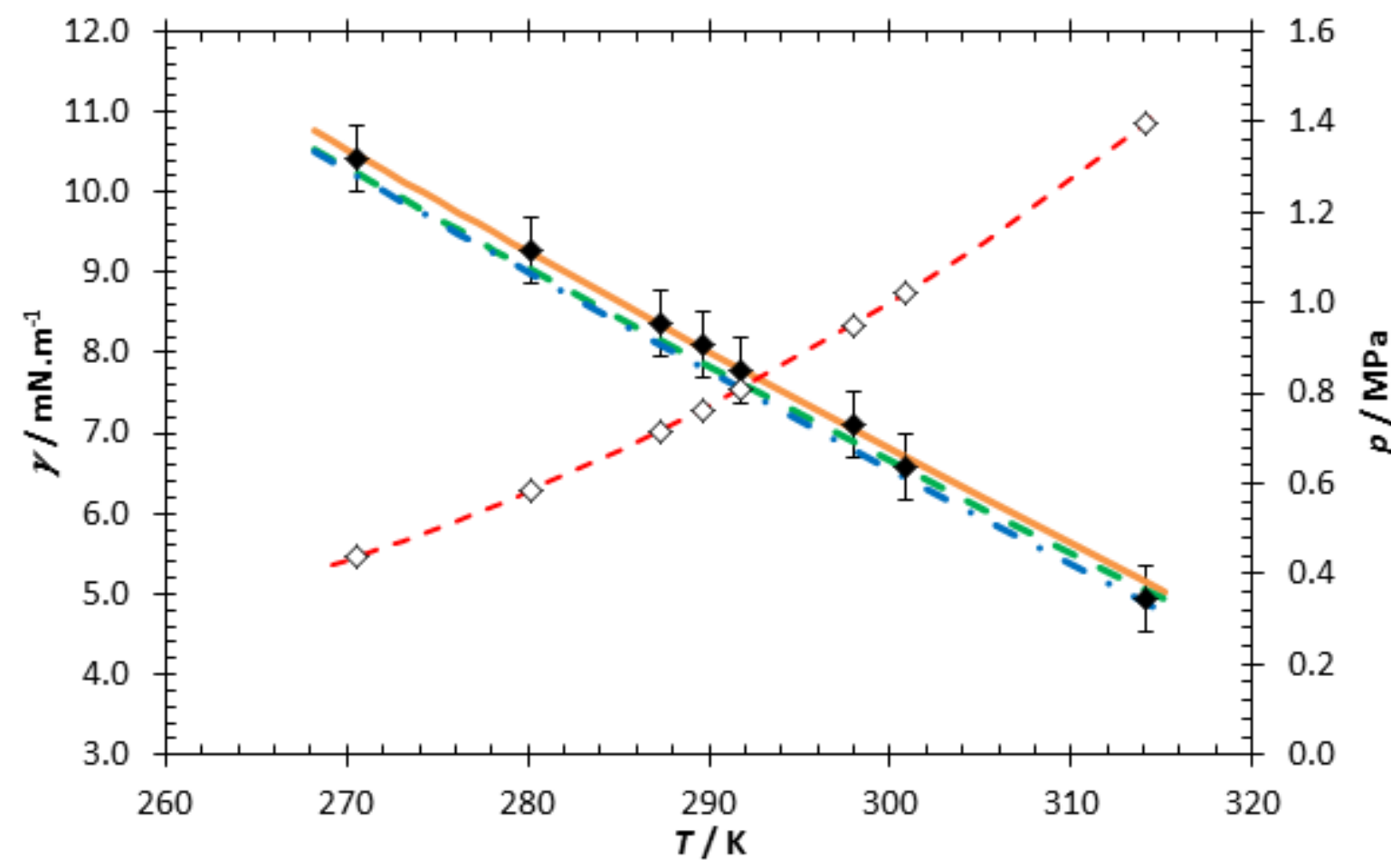

Figure 2: Propane surface tension and vapour pressure measurements. This work: $\diamond$, surface tension; $\diamond$, vapour pressure. Calculated surface tensions: — , Mulero et al. ${ }^{3}$ (REFPROP); - MCSA (Multiflash); - "- , LGT (Multiflash). Calculated vapour pressure: $\cdots \cdot \cdots$, Lemmon et al. ${ }^{52}$ (REFPROP).

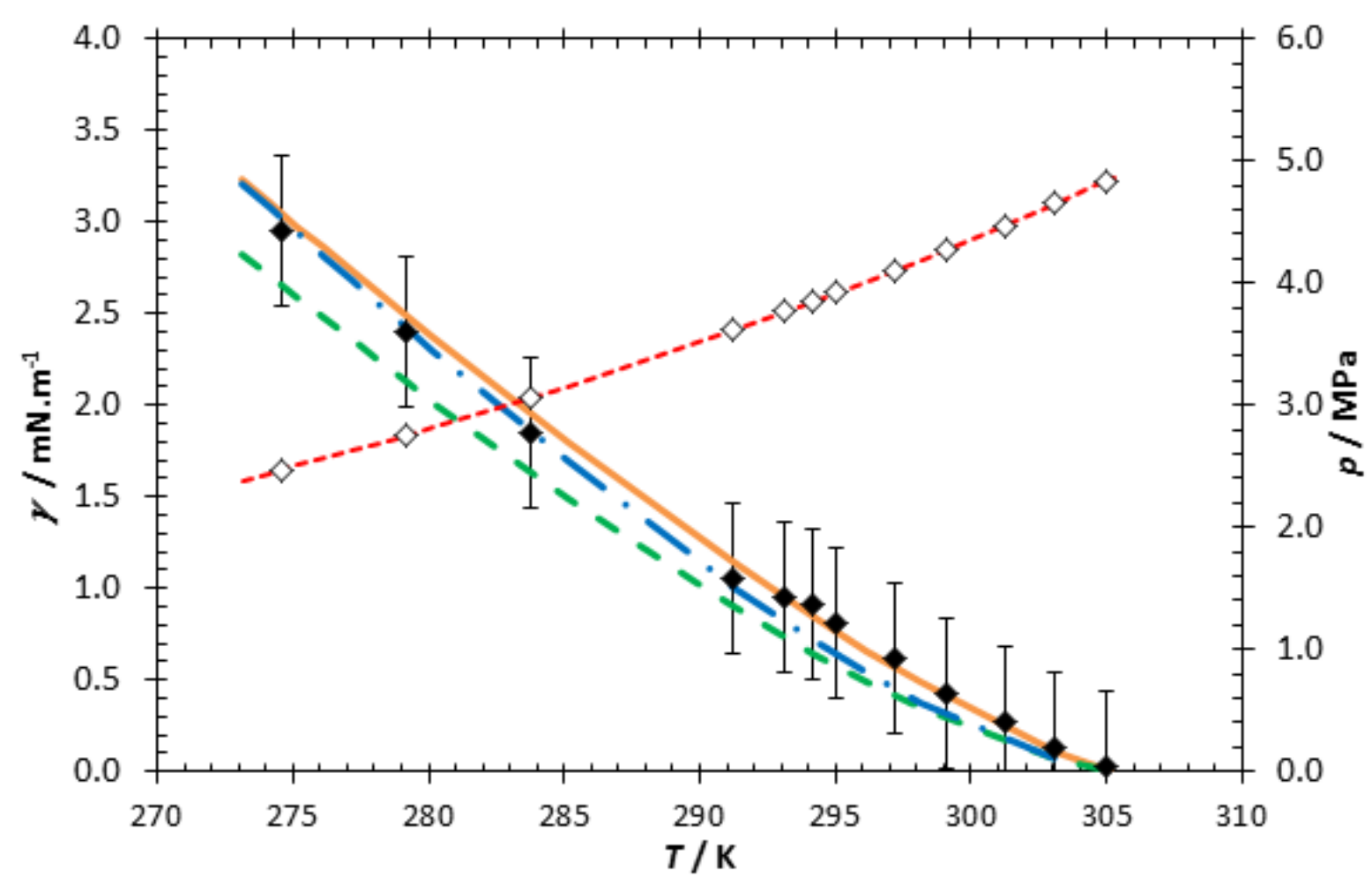

Figure 3: Ethane surface tension and vapour pressure measurements. This work: $\downarrow$, surface tension; $\diamond$, vapour pressure. Calculated surface tensions: - , Mulero et al. ${ }^{3}$ (REFPROP); - MCSA (Multiflash); - "- , LGT (Multiflash). Calculated vapour pressure: $\cdot \cdots \cdot$, Bücker and Wagner ${ }^{54}$ (REFPROP). 
The experimental surface tension data for pure ethane and propane from this work and literature data are shown in

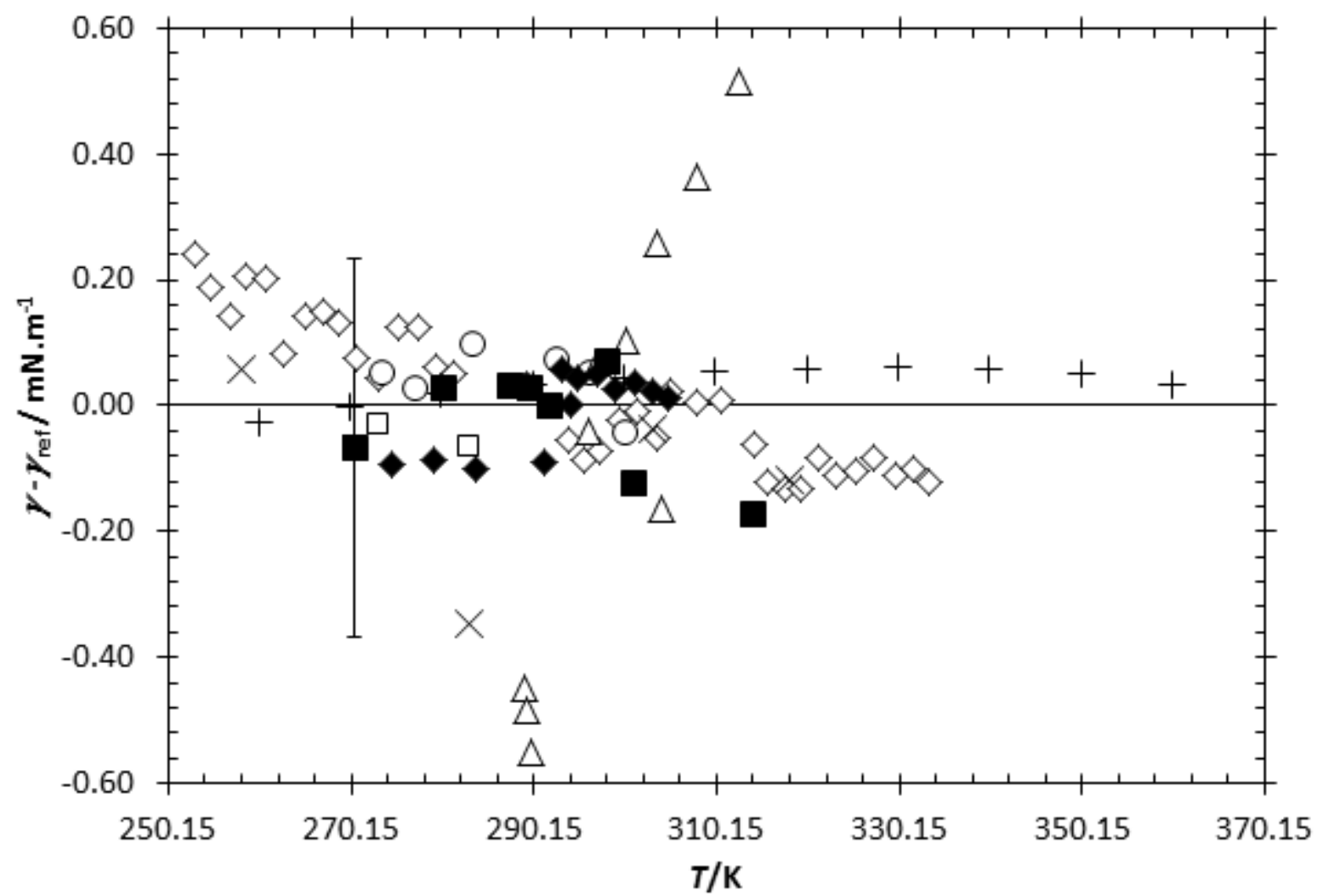

Figure 4 as deviations from Mulero et al. ${ }^{3}$, the reference correlation used for these pure fluids. The present data are consistent with the reference correlations well within their estimated uncertainty, and have comparable deviations to the other literature data which were used in the development of the correlations. The data of Katz and Saltman ${ }^{58}$ for propane and one value from the measurements of Weinaug and Katz ${ }^{9}$ for propane appear to be outliers. 


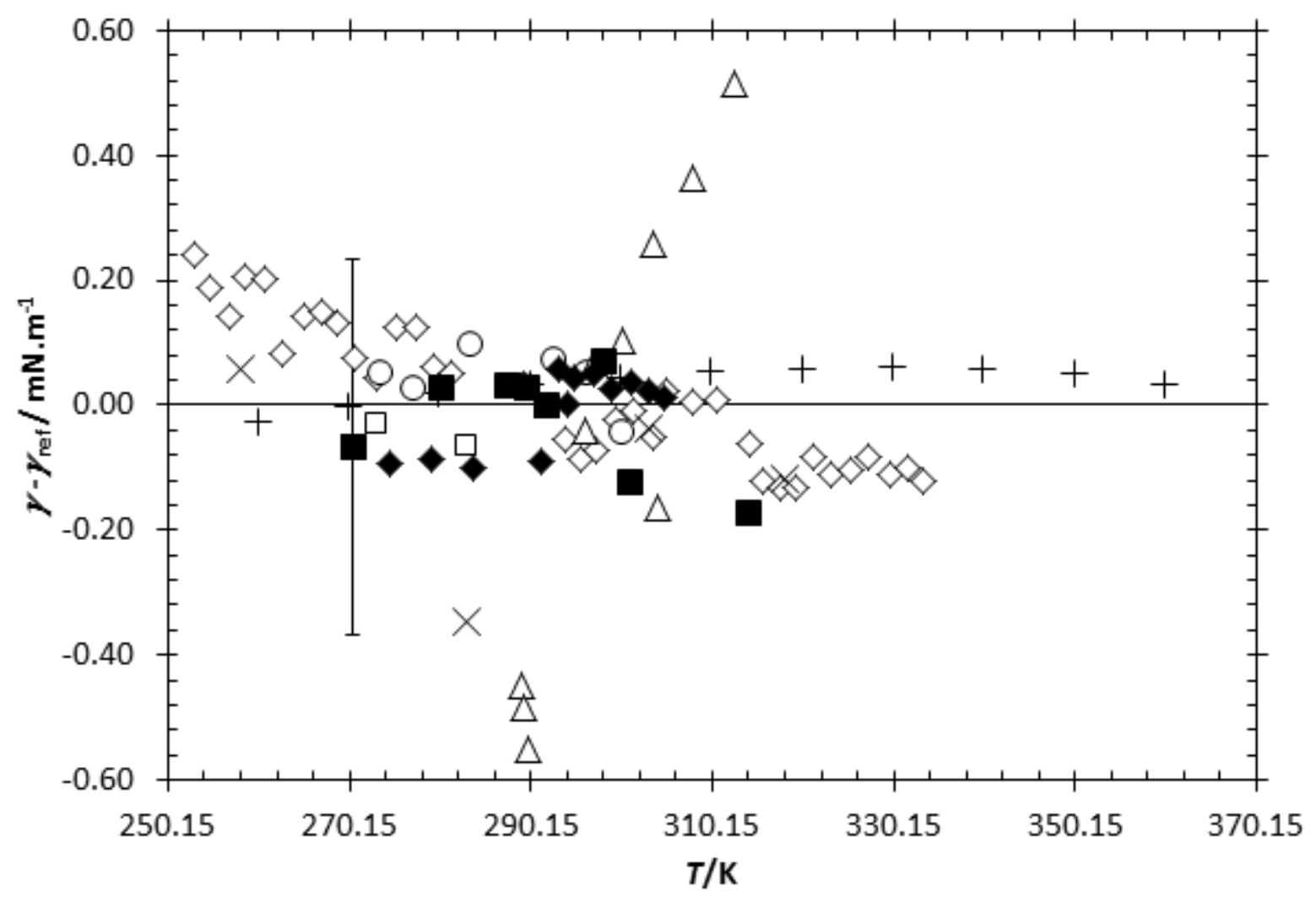

Figure 4: Deviation between measured surface tensions, $v$, and reference correlations of Mulero et al, $\gamma_{\text {ref, }}$ implemented in REFPROP ${ }^{3}$ for pure ethane and propane as a function of temperature. This work: $\diamond$, Ethane; $\mathbf{\square}$, Propane. Katz and Saltman ${ }^{58}: \bigcirc$, Ethane; $\triangle$,Propane. Baidakov et al. ${ }^{24}: \square$, Ethane; + , Propane. Lin and Duan ${ }^{59}: \diamond$, Propane. Weinaug and Katz ${ }^{9}: \times$, Propane.

Validation of the critical point determinations using both methods was completed using pure ethane In contrast to the mixtures, critical opalescence in pure ethane was observed by increasing the temperature of the system by $0.4 \mathrm{~K}$ and waiting until the temperature of the system reached steady state. The critical point is shown in Figure 5 and the critical parameters determined with the two methods are listed in Table 7 and compared to other values for this reference system. For ethane the critical opalescence measurement shows a deviation from the condition reported by Funke et al. ${ }^{60}$ of $+0.07 \mathrm{~K}$ in the critical temperature and $-0.002 \mathrm{MPa}$ in the critical pressure, both of which are within the corresponding experimental uncertainty. The critical point estimated by extrapolation to the zero surface tension condition differs from the values reported by Funke et al. ${ }^{60}$ by $0.17 \mathrm{~K}$ in critical temperature and $0.018 \mathrm{MPa}$ in critical pressure. The former is slightly smaller than the statistical uncertainty associated with the fit, while the latter is about a factor of two larger. This suggests that the critical opalescence method provides a more accurate measurement of the critical point.

Table 7: Critical Temperature and Pressure for ethane showing measured critical opalescence and extrapolation of critical point from surface tension data in this work in comparison with literature data from Funke et al. ${ }^{60}$ used in REFPROP and Multiflash software packages. The critical temperatures and pressures have their standard uncertainties listed.

\begin{tabular}{|c|c|c|}
\hline & $T / \mathrm{K}$ & $p / \mathrm{MPa}$ \\
\hline Critical Opalescence & $305.39 \pm 0.08$ & $4.870 \pm 0.002$ \\
\hline Zero Surface Tension Estimation & $305.49 \pm 0.22$ & $4.890 \pm 0.008$ \\
\hline
\end{tabular}




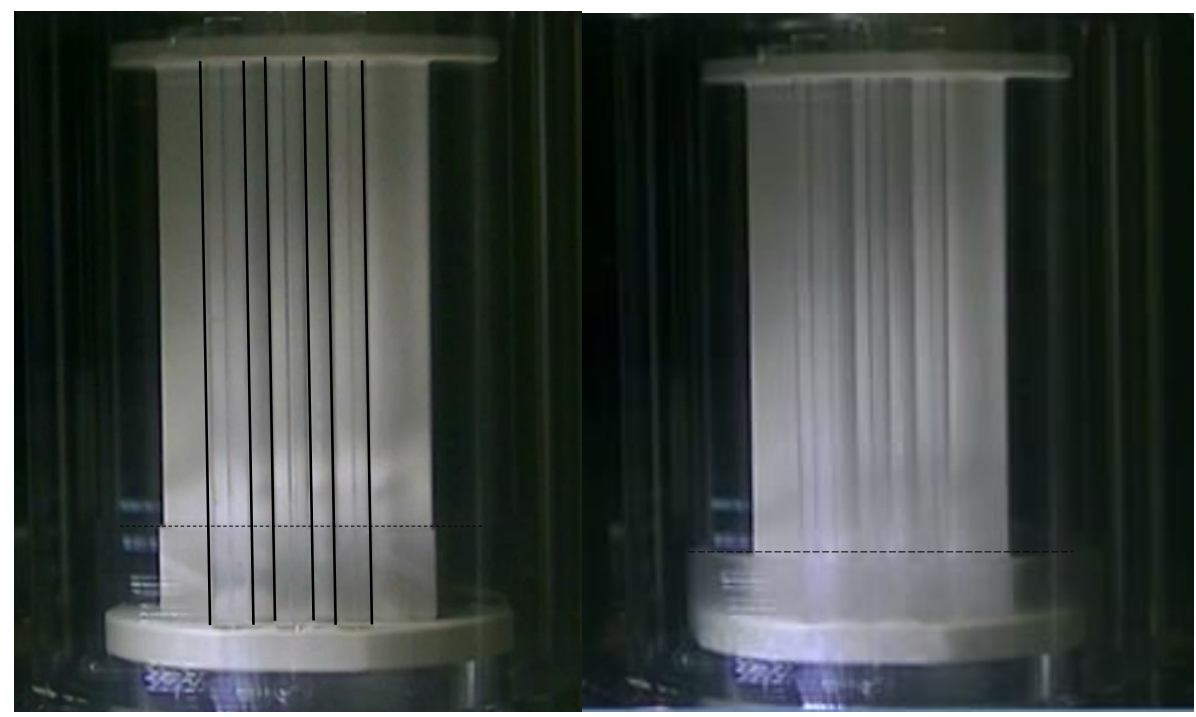

Figure 5: Ethane in visual cell transitioning from a state (left) with clearly distinct liquid and vapour phases to one with cloudiness (right) due to critical opalescence once the critical temperature and

pressure was reached. For clarity the approximate nominal level of the bulk interface (prior to disappearance) are shown with a dashed line, and the outside of the capillaries are shown with solid vertical lines.

\section{Mixture Results and Discussion}

The measured surface tension for the binary mixtures of methane and propane at $T=(272.23$, 285.51 and 303.34) $\mathrm{K}$ are listed in Table 8 together with the measured pressure, overall methane mole fraction and the liquid methane mole fraction calculated using the GERG-2008 EOS. For reference, the phase densities predicted with the GERG-2008 EOS are also shown. The experimental uncertainties in the surface tension, due mainly to the parallax errors associated with the height rise measurements made with the cathetometer, as well as the uncertainties in pressure and temperature are as shown in Table 4.

Figures 6, 7 and 8 show the surface tension values for methane + propane at $T=(272.23,285.51$ and 303.34) $\mathrm{K}$ compared with the predicted values from models implemented in REFPROP 9.1, REFPROP 9.2( $\beta$ ) and Multiflash 4.4. Each isotherm shows an initial pure propane surface tension measurement, with subsequent surface tension measurements occurring with increasing pressure and methane mole fraction.

Table 8: Experimental Values Surface Tension, $\gamma$, for the Methane (1) + Propane (2) Mixture at $T=$ $(272.2,285.5,303.3) \mathrm{K}$ Using the Calculated Liquid Density, $\rho_{l}$, and Vapour Density, $\rho_{v}$, at Pressure, $p$, and methane mole fraction in the bulk, $z_{1}$ (measured), and in the liquid phase, $x_{1}$ (calculated). ${ }^{c}$

\begin{tabular}{|c|c|c|c|c|c|c|c|}
\hline \multicolumn{8}{|c|}{$T \cong 272.2 \mathrm{~K}$} \\
\hline$z_{1}$ & $u\left(z_{1}\right)$ & $x_{1}$ & $T / K$ & $p / \mathrm{MPa}$ & $\rho_{\mathrm{L}} / \mathrm{kg} \cdot \mathrm{m}^{-3}$ & $\rho_{\mathrm{V}} / \mathrm{kg} \cdot \mathrm{m}^{-3}$ & $\gamma / \mathrm{mN} \cdot \mathrm{m}^{-1}$ \\
\hline 0.0000 & 0.0 & 0 & 271.77 & 0.4560 & 530.45 & 9.94 & 10.30
\end{tabular}




\begin{tabular}{|c|c|c|c|c|c|c|c|}
\hline 0.2345 & $2.6 \times 10^{-3}$ & 0.0508 & 272.14 & 1.1680 & 519.67 & 16.48 & 9.38 \\
\hline 0.3953 & $3.1 \times 10^{-3}$ & 0.105 & 272.24 & 1.9345 & 507.78 & 23.65 & 7.99 \\
\hline 0.4688 & $3.3 \times 10^{-3}$ & 0.139 & 272.08 & 2.4160 & 500.20 & 28.38 & 7.06 \\
\hline 0.5772 & $3.6 \times 10^{-3}$ & 0.206 & 272.34 & 3.3996 & 483.17 & 38.91 & 5.99 \\
\hline 0.6454 & $3.8 \times 10^{-3}$ & 0.265 & 272.29 & 4.2645 & 467.23 & 49.13 & 4.85 \\
\hline 0.6946 & $3.9 \times 10^{-3}$ & 0.320 & 272.25 & 5.0762 & 450.94 & 59.84 & 3.54 \\
\hline 0.7501 & $4.1 \times 10^{-3}$ & 0.391 & 272.33 & 6.1366 & 427.09 & 76.04 & 2.63 \\
\hline 0.7817 & $4.2 \times 10^{-3}$ & 0.450 & 272.10 & 6.9860 & 405.38 & 91.53 & 1.71 \\
\hline 0.7997 & $4.2 \times 10^{-3}$ & 0.493 & 272.28 & 7.6063 & 387.13 & 105.03 & 1.36 \\
\hline 0.8196 & $4.3 \times 10^{-3}$ & 0.554 & 272.35 & 8.4275 & 358.57 & 127.40 & 0.51 \\
\hline \multicolumn{8}{|c|}{$T \cong 285.5 \mathrm{~K}$} \\
\hline$z_{1}$ & $u\left(z_{1}\right)$ & $x_{1}$ & $T / K$ & $p / \mathrm{MPa}$ & $\rho_{\mathrm{L}} / \mathrm{kg} \cdot \mathrm{m}^{-3}$ & $\rho_{\mathrm{v}} / \mathrm{kg} \cdot \mathrm{m}^{-3}$ & $\gamma / \mathrm{mN} \cdot \mathrm{m}^{-1}$ \\
\hline 0.0000 & 0.0 & 0.000 & 285.35 & 0.6806 & 508.67 & 15.47 & 8.37 \\
\hline 0.0745 & $2.0 \times 10^{-3}$ & 0.0217 & 285.35 & 1.0126 & 507.02 & 17.95 & 7.89 \\
\hline 0.1845 & $2.2 \times 10^{-3}$ & 0.0609 & 285.37 & 1.6121 & 498.41 & 23.61 & 7.13 \\
\hline 0.3188 & $2.5 \times 10^{-3}$ & 0.122 & 285.76 & 2.5679 & 483.44 & 33.18 & 6.10 \\
\hline 0.3908 & $2.8 \times 10^{-3}$ & 0.165 & 285.65 & 3.2339 & 472.79 & 40.28 & 5.02 \\
\hline 0.5429 & $3.1 \times 10^{-3}$ & 0.279 & 285.55 & 5.0415 & 440.15 & 62.65 & 3.10 \\
\hline 0.5853 & $3.5 \times 10^{-3}$ & 0.323 & 285.50 & 5.7425 & 425.67 & 72.98 & 2.35 \\
\hline 0.6433 & $3.6 \times 10^{-3}$ & 0.398 & 285.39 & 6.9025 & 398.38 & 93.26 & 1.57 \\
\hline 0.7001 & $3.8 \times 10^{-3}$ & 0.474 & 285.55 & 8.0363 & 365.01 & 119.61 & 0.76 \\
\hline 0.7192 & $3.9 \times 10^{-3}$ & 0.525 & 285.50 & 8.7242 & 339.01 & 141.64 & 0.34 \\
\hline \multicolumn{8}{|c|}{$\mathrm{T} \cong 303.3 \mathrm{~K}$} \\
\hline$z_{1}$ & $u\left(z_{1}\right)$ & $x_{1}$ & $T / K$ & $p / \mathrm{MPa}$ & $\rho_{\mathrm{L}} / \mathrm{kg} \cdot \mathrm{m}^{-3}$ & $\rho_{\mathrm{V}} / \mathrm{kg} \cdot \mathrm{m}^{-3}$ & $\gamma / \mathrm{mN} \cdot \mathrm{m}^{-1}$ \\
\hline 0.0000 & 0.0 & 0.000 & 303.37 & 1.0831 & 484.39 & 23.45 & 6.48 \\
\hline 0.1910 & $1.9 \times 10^{-3}$ & 0.117 & 303.15 & 3.0760 & 454.80 & 45.64 & 4.12 \\
\hline 0.3056 & $2.6 \times 10^{-3}$ & 0.201 & 303.45 & 4.5101 & 430.14 & 63.77 & 2.99 \\
\hline 0.4252 & $3.0 \times 10^{-3}$ & 0.318 & 303.35 & 6.4541 & 388.58 & 96.16 & 1.27 \\
\hline 0.4844 & $3.0 \times 10^{-3}$ & 0.389 & 303.37 & 7.5420 & 358.06 & 121.88 & 0.62 \\
\hline 0.5144 & $3.1 \times 10^{-3}$ & 0.433 & 303.37 & 8.1713 & 334.51 & 142.95 & 0.27 \\
\hline
\end{tabular}

${ }^{c}$ Standard uncertainties in temperature $u(T)=0.08 \mathrm{~K}, u(p) / p=0.036 \%, u(\gamma)=0.34 \mathrm{mN} \cdot \mathrm{m}^{-1}$. 


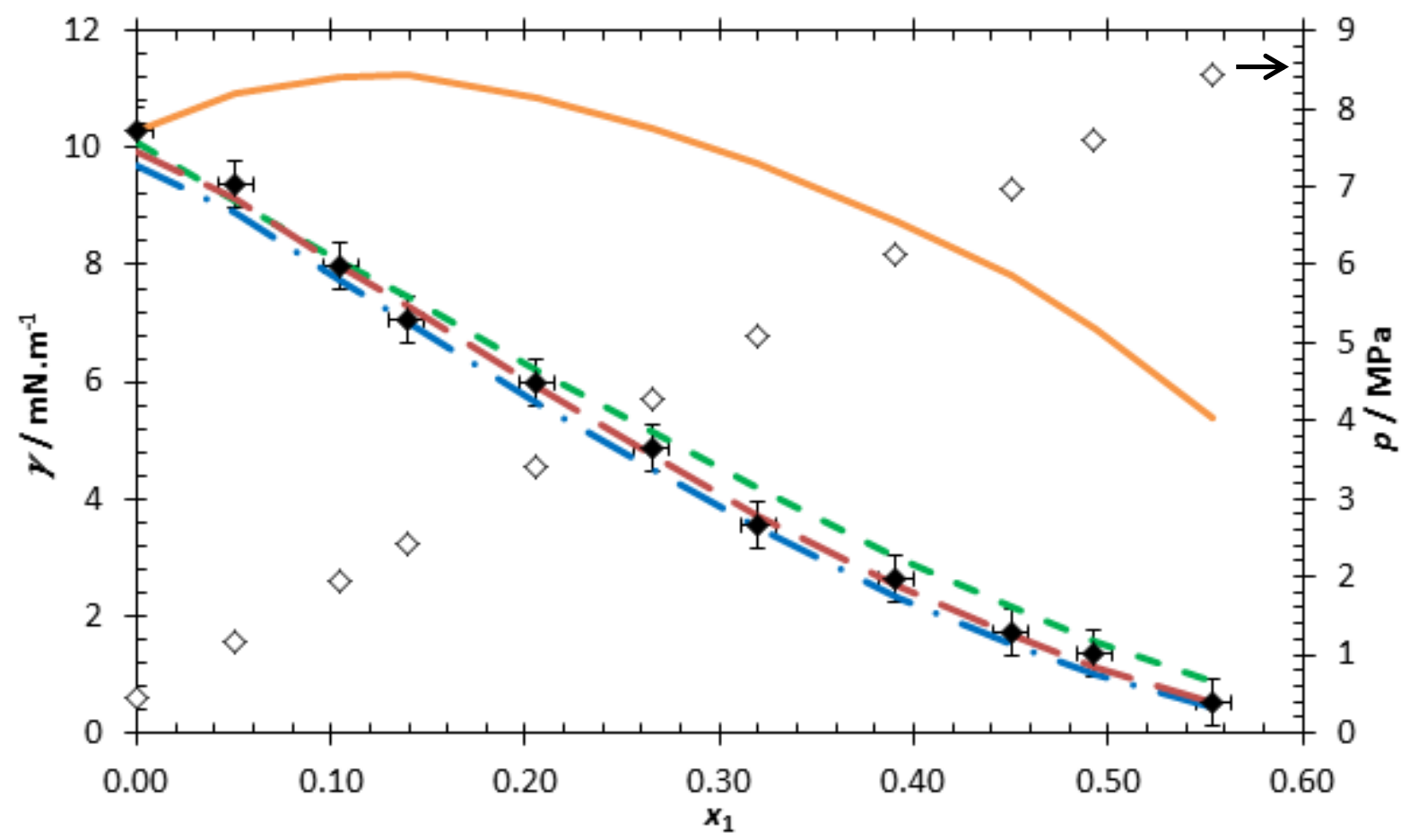

Figure 6: Comparison between measured and predicted surface tension values $\gamma$ at $T=(272.23 \pm$ $0.12) \mathrm{K}$ for methane (1) + propane (2). The measured surface tension data are shown as $\boldsymbol{\nabla}$. Surface tensions were calculated with models implemented in: —, REFPROP 9.1, - - REFPROP 9.2( $\beta$ ) and in Multiflash - -, LGT and - - - MCSA. The measured pressure is plotted on the right axis and shown as $\diamond$.

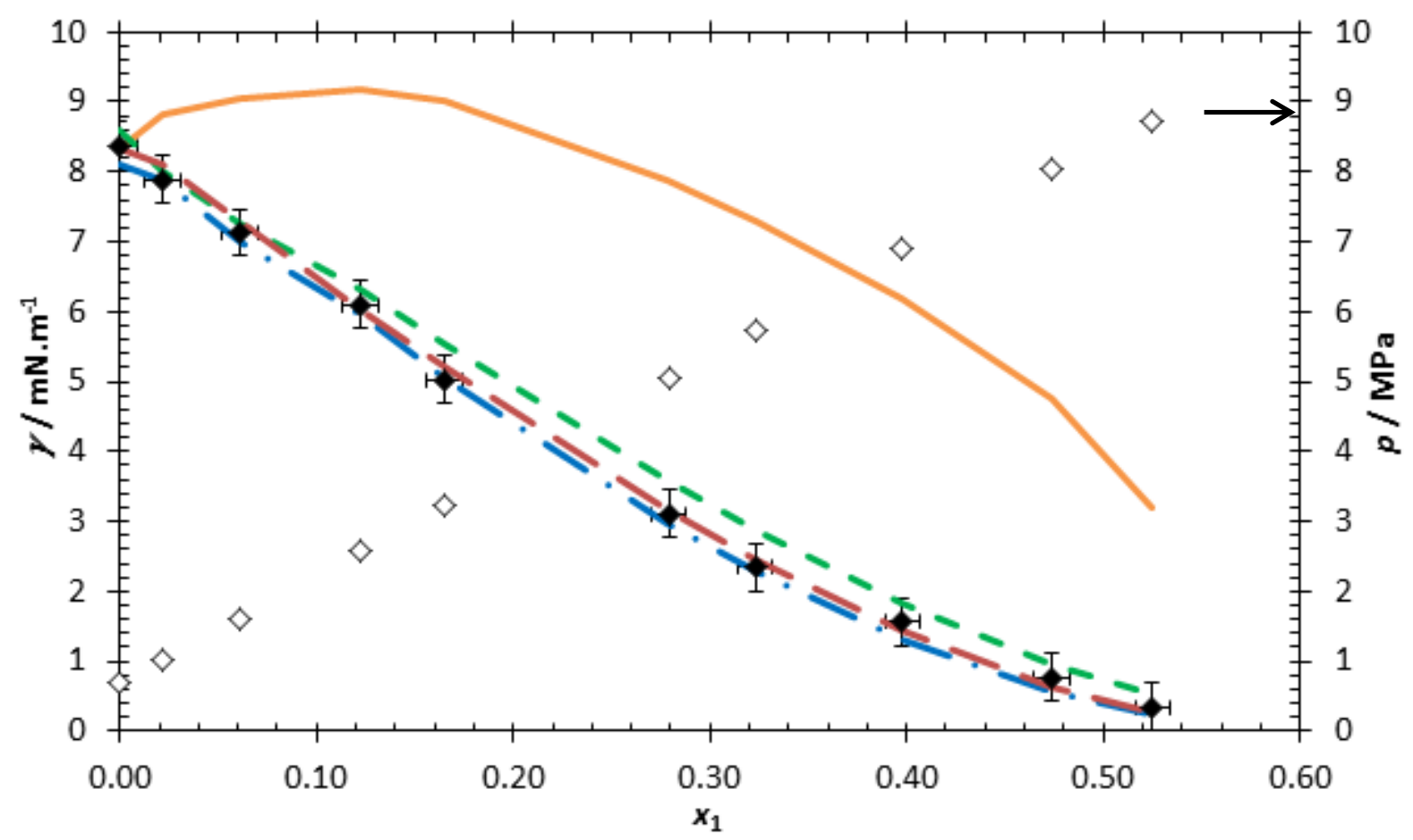

Figure 7: Comparison between measured and predicted surface tension values $\gamma$ at $T=(285.51 \pm$ $0.23) \mathrm{K}$ for methane (1) + propane (2). The measured surface tension data are shown as $\downarrow$. Surface tensions were calculated with models implemented in: — , REFPROP 9.1, - - REFPROP 9.2( $\beta$ ) and in Multiflash - -, LGT and - - - MCSA. The measured pressure is plotted on the right axis and shown as $\diamond$. 


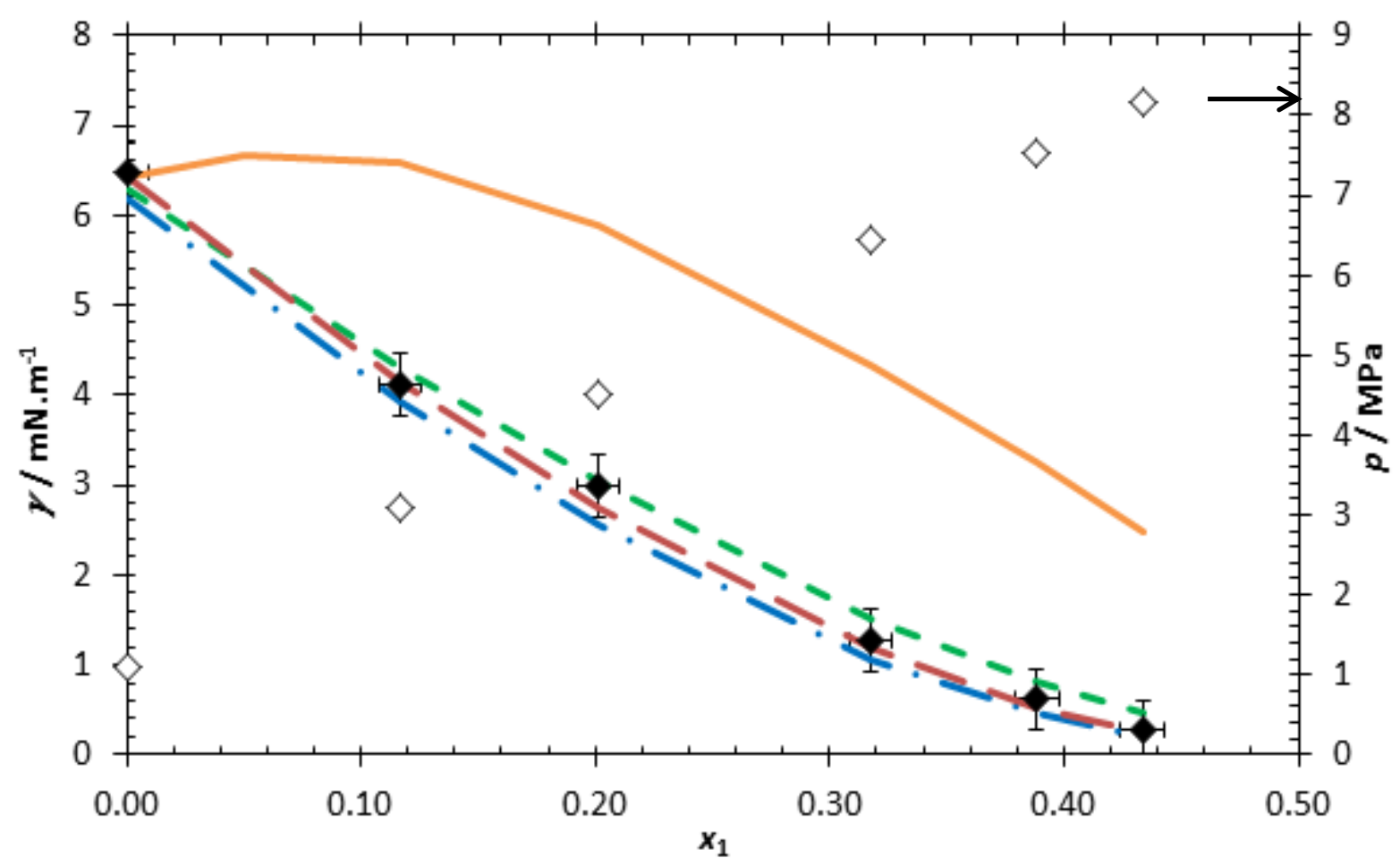

Figure 8: Comparison between measured and predicted surface tension values $\gamma$ at $T=(303.34 \pm$ $0.13) \mathrm{K}$ for methane (1) + propane (2). The measured surface tension data are shown as $\boldsymbol{}$. Surface tensions were calculated with models implemented in: - , REFPROP 9.1, - -, REFPROP 9.2( $\beta$ ) and in Multiflash -- , LGT and $-=$, MCSA. The measured pressure is plotted on the right axis and shown as $\diamond$.

For the three mixture isotherms it is clear that the surface tension model implemented in the currently available REFPROP 9.1, has a large discrepancy with the measured surface tensions and a completely different trend with composition. The maximum deviation of $6.25 \mathrm{mN} \cdot \mathrm{m}^{-1}$ occurs for the $272.23 \mathrm{~K}$ isotherm at a pressure of $6.14 \mathrm{MPa}$, where the measured surface tension is only 2.64 $\mathrm{mN} \cdot \mathrm{m}^{-1}$. In contrast the measured surface tension data are generally consistent with predictions from the models implemented in Multiflash. Of these models, the predictions of the Macleod Sugden Advanced model were in slightly better agreement than the predictions of the Linear Gradient Theory model, which may be attributable to the latter's use of the Peng Robinson Advanced (PRA) EOS for the phase densities rather than the GERG-2008 EOS.

These results led us to contact the developers of the REFPROP software to understand the reason for the mixture surface tensions predictions generated by the implementation of the Moldover and Rainwater model. The developers indicated that the details of the model's implementation were no longer available, and instead they implemented the Parachor model for use with hydrocarbon mixtures within a new version of the software REFPROP 9.2( $\beta)$. As shown in Figure 9, the implementation of this mixture Parachor model is in excellent agreement with surface tension data for these mixtures reported here and in the literature ${ }^{8,11}$. In particular, the predicted surface tension values at the conditions measured in this work agree with the present measurements within experimental uncertainty for all isotherms and at all compositions. 


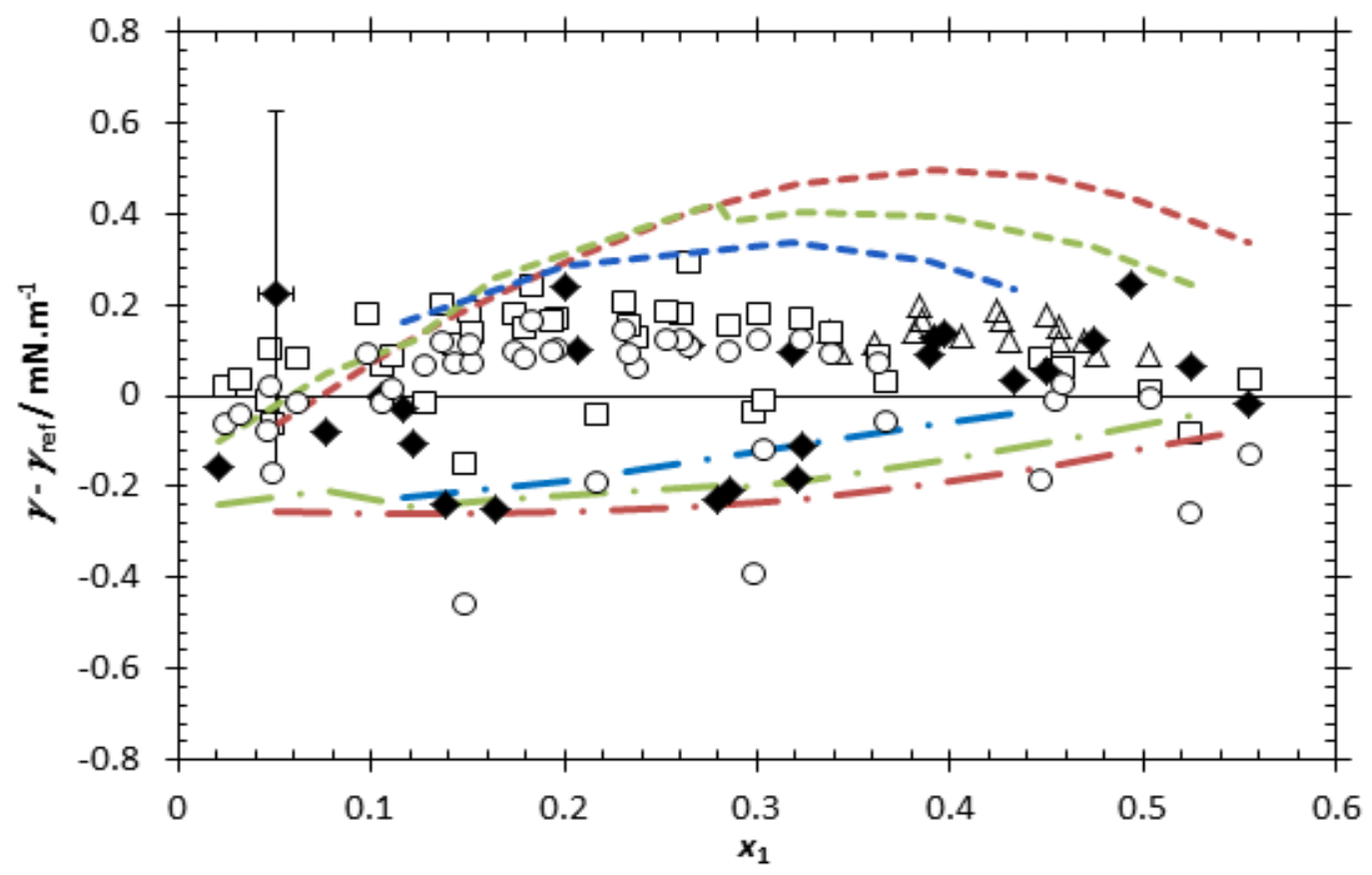

Figure 9: Deviation between measured surface tensions, $\gamma$, and Parachor model implemented in REFPROP 9.2( $(\beta), \nu_{\text {ref. }} \bullet$, This work; $\square$, Weinaug and Katz ${ }^{9} ; O$,Updated data of Weinaug and Katz ${ }^{9}$; $\triangle$, Haniff and Pearce ${ }^{12}$, Predictive Models in Multiflash: MCSA: $-"-, T=272.23 \mathrm{~K},-=-T=$ $285.51 \mathrm{~K},-\square, T=303.34 \mathrm{~K} ; \mathrm{LGT}:--, T=272.23 \mathrm{~K},--, T=285.51 \mathrm{~K}--, T=303.34 \mathrm{~K}$.

The surface tension data of Weinaug and Katz ${ }^{9}$ and Haniff and Pearce ${ }^{12}$ for methane and propane mixtures exhibit similar deviations from the predictions of the REFPROP 9.2( $\beta$ ) Parachor model as the data presented in this work. In Figure 9, the deviations of the Weinaug and Katz ${ }^{9}$ data are shown twice, with the original surface tension results reported in the paper having an r.m.s. deviation of $0.13 \mathrm{mN} \cdot \mathrm{m}^{-1}$ from REFPROP $9.2(\beta)$. Additionally, updated values were obtained by recalculating the surface tensions from the recorded heights and updated density predictions made using GERG-2008 EOS. At first, however, these updated values increase the r.m.s deviation to 0.14 $\mathrm{mN} \cdot \mathrm{m}^{-1}$ because of major variations in the liquid density calculations for lower temperature measurements. The updated data from Weinaug and Katz ${ }^{9}$ clearly show two outliers which corresponded to measurements of low methane content mixtures along the lowest isotherm $T=258$ K. The r.m.s deviation when excluding these two points reduces to $0.11 \mathrm{mN} \cdot \mathrm{m}^{-1}$. The Haniff and Pearce ${ }^{12}$ data show a similar r.m.s deviation of $0.14 \mathrm{mN} \cdot \mathrm{m}^{-1}$. The r.m.s deviation for the data in this work was $0.15 \mathrm{mN} \cdot \mathrm{m}^{-1}$, which is well below the uncertainty of the surface tension measurement and close to the r.m.s deviation of the other methane and propane experimental data. Figure 9 also shows a comparison of surface tension predictions for these same conditions made with the MCSA Parachor model and the Linear Gradient Theory model, both implemented in Multiflash 4.4. All the models are generally consistent with the data measured here and from the literature, within experimental uncertainty; however the surface tensions predicted using the MCSA model are generally smaller than those measured, while those predicted using the LGT model are generally larger.

The mixture critical points were determined for each of the three isotherms studied, $T=(272,286$ and 303) $\mathrm{K}$, following completion of the surface tension measurements. The critical point was determined by two independent methods: the visualisation of critical opalescence and extrapolation to zero surface tension. Photographs of the critical opalescence for $T=285.68 \mathrm{~K}$ are shown in Figure 
10 , with videos of the critical opalescence observation included as supplementary information. The first indication that the fluid had reached its critical point was the transition from a system with a distinct bulk liquid meniscus to a uniform nearly clear fluid. Then, once the recirculation pump was turned on, the clear fluid began to appear light blue at the interface, before the interface lost its rigidity, moved rapidly and disappeared with all the fluid at the base of the cell turning a light blue. The blue colouring at critical opalescence is shown in Figure 10 and Video 1. For each isotherm, the measured bubble point pressures are shown together with the critical points determined by both methods, as a function of overall composition and pressure in Figures 11,12 and 13. Also shown are the phase envelopes and mixture critical points predicted for each isotherm using the GERG-2008 and PRA EOS at the $z_{1}$ measured for the critical opalescence condition.

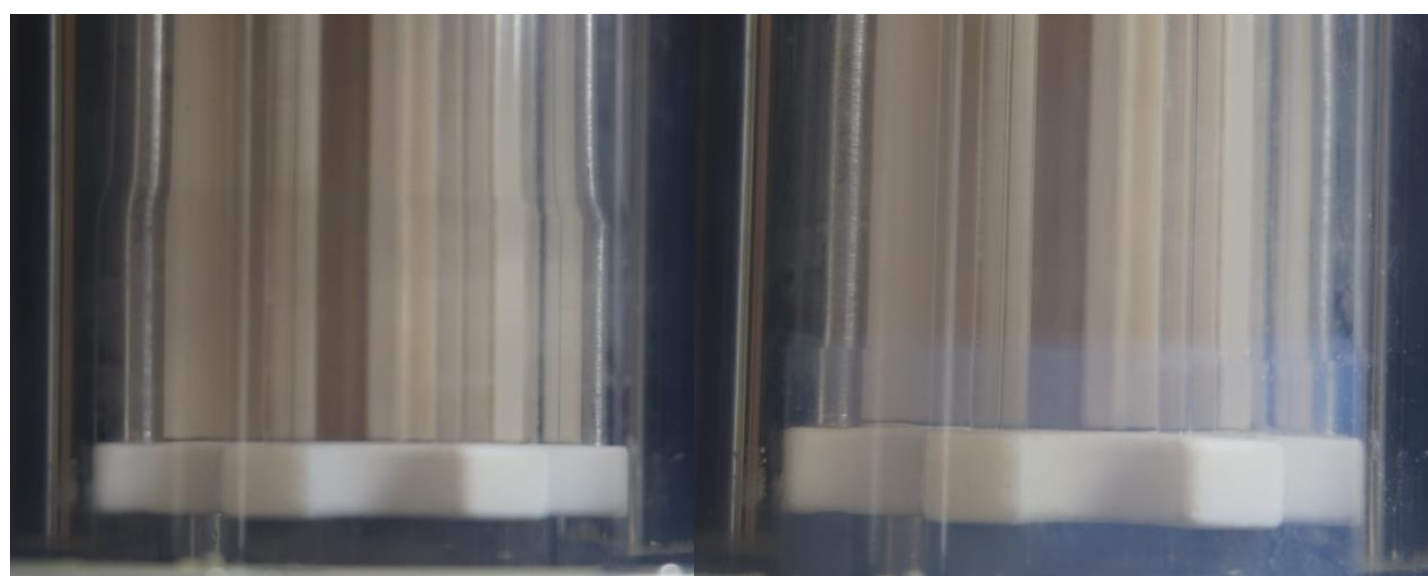

Figure 10: Visual cell during the transition to critical opalescence (left) when bulk liquid meniscus disappeared, and (right) when the recirculation pump was turned on and blue colouring appeared.

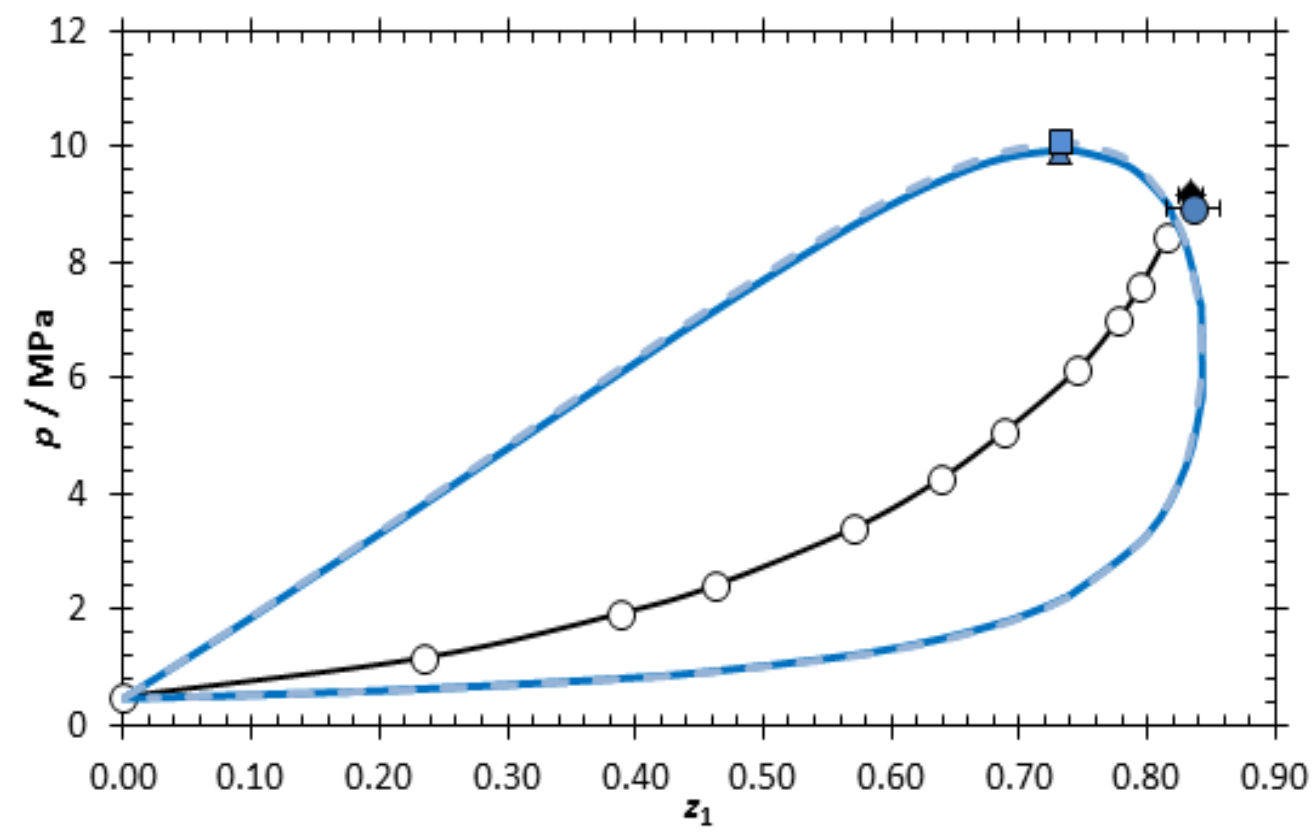

Figure 11: Measured bubble pressures and critical point of methane (1) + propane (2) along the isotherm $T=272.35 \mathrm{~K}$ as a function of overall methane mole fraction. - $-\mathrm{O}$-, Measured bubble pressures; $\bigcirc$, extrapolated zero surface tension; $\diamond$, critical opalescence measurement. Also shown

are phase envelope calculations corresponding to the $z_{1}$ measured at the critical opalescence condition. - GERG-2008 EOS; - - PRA EOS. Predicted mixture critical points: $\square$, PRA EOS, and $\triangle$, GERG-2008 EOS. 


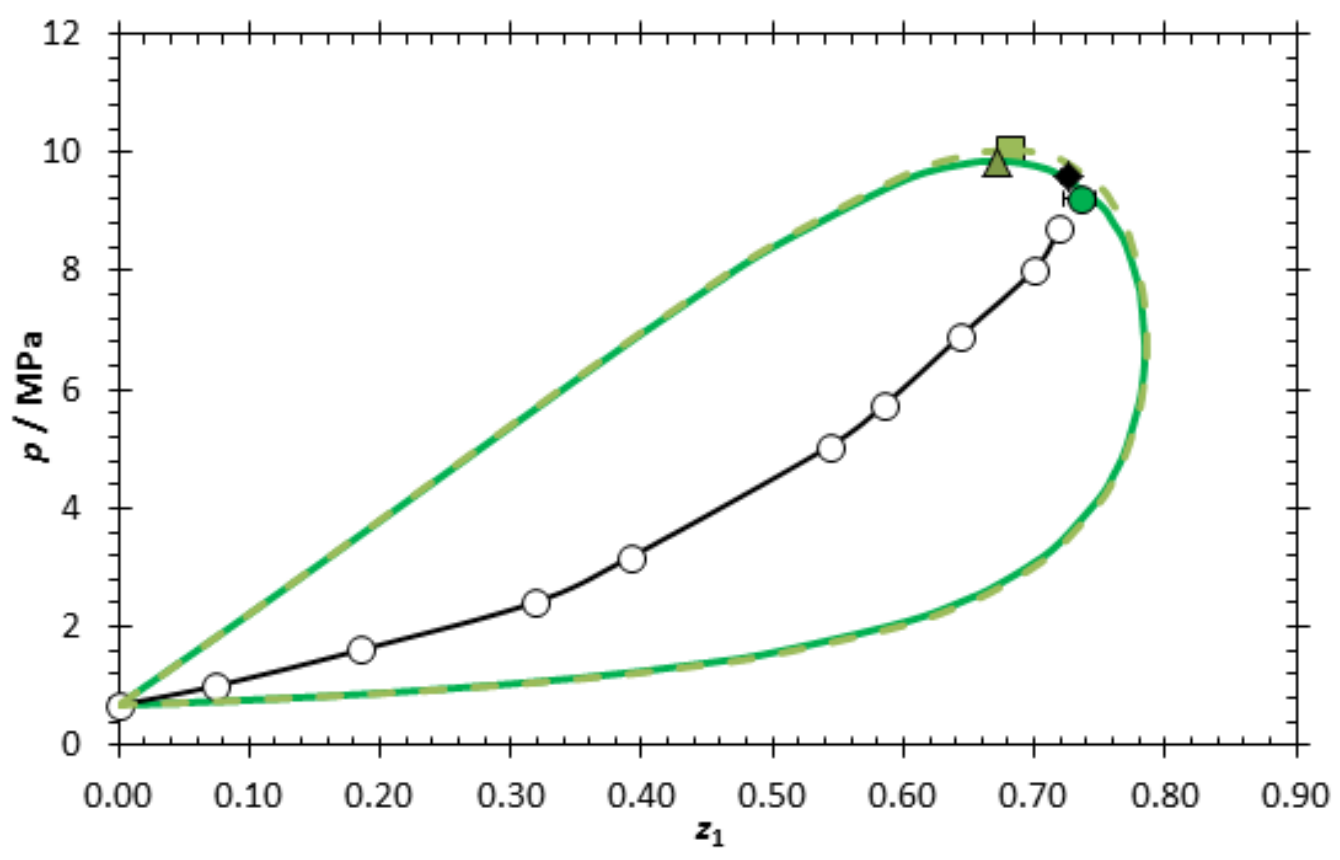

Figure 12: Measured bubble pressures and critical point of methane (1) + propane (2) along the isotherm $T=285.68 \mathrm{~K}$ as a function of overall methane mole fraction. $-\mathrm{O}$-, Measured bubble pressures; $\bigcirc$, extrapolated zero surface tension; $\diamond$, critical opalescence measurement. Also shown are phase envelope calculations corresponding to the $z_{1}$ measured at the critical opalescence condition. - - GERG-2008 EOS; - -, PRA EOS. Predicted mixture critical points: $\square$, PRA EOS, and $\triangle$, GERG-2008 EOS.

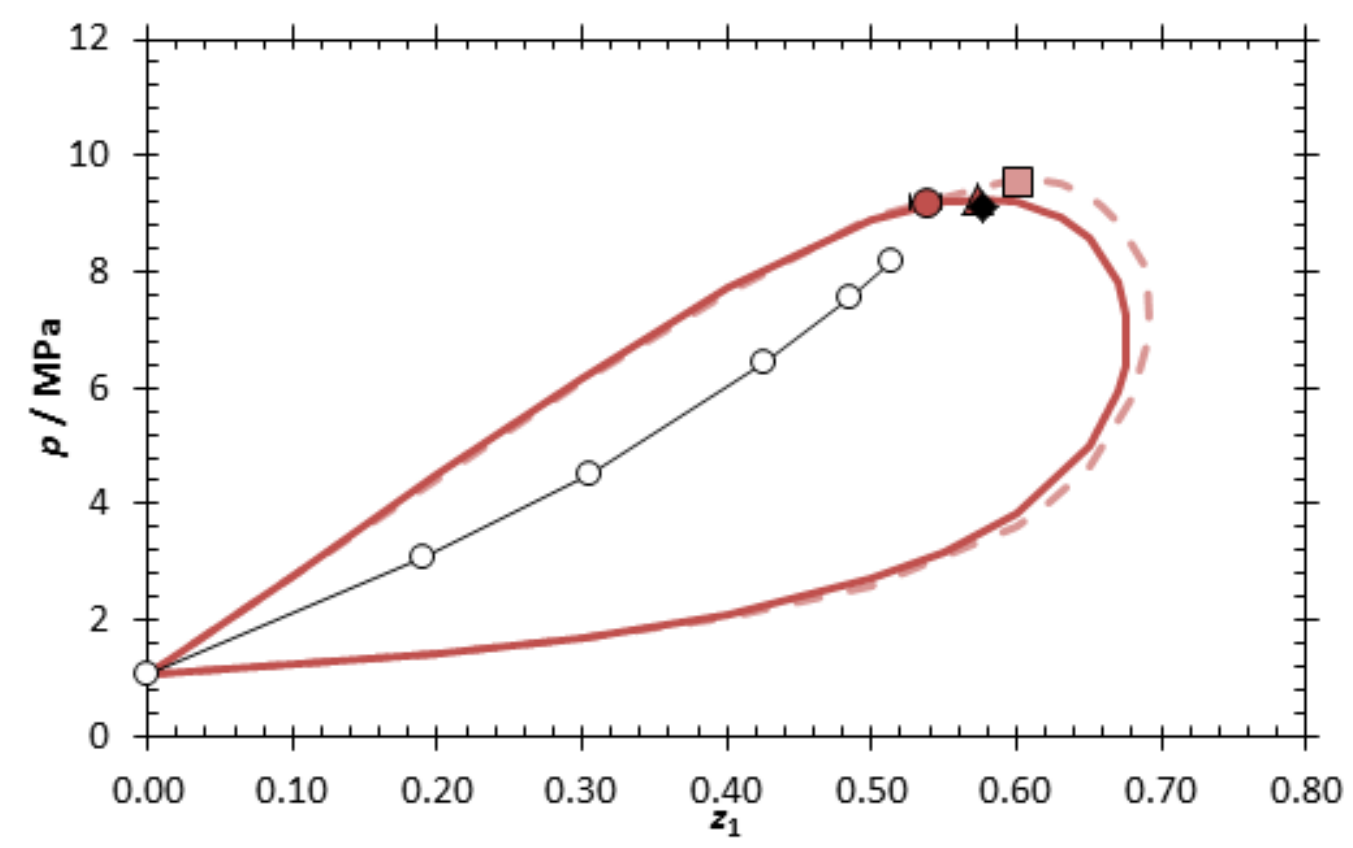

Figure 13: Measured bubble pressures and critical point of methane (1) + propane (2) along the isotherm $T=303.51 \mathrm{~K}$ as a function of overall methane mole fraction. $-\mathrm{O}$-, Measured bubble pressures; $\bigcirc$, extrapolated zero surface tension; $\diamond$, critical opalescence measurement. Also shown are phase envelope calculations corresponding to the $z_{1}$ measured at the critical opalescence condition. —, GERG-2008 EOS; - - PRA EOS. Predicted mixture critical points: $\square$,PRA EOS, and $\triangle$, GERG-2008 EOS. 
Table 9: Critical point parameters temperature, $T_{\mathrm{c}}$, methane composition, $z_{1}$, and pressure, $p_{\mathrm{c}}$, for methane (1) + propane (2) mixtures at each isotherm based on critical opalescence measurement. ${ }^{d}$

\begin{tabular}{|c|c|c|c|}
\hline $\boldsymbol{T}_{\mathbf{c}} / \mathbf{K}$ & $\mathbf{z}_{\mathbf{1}}$ & $\boldsymbol{u}\left(\mathbf{z}_{\mathbf{1}}\right)$ & $\boldsymbol{p}_{\mathbf{c}} / \mathbf{M P a}$ \\
\hline 272.35 & 0.8344 & $4.3 \times 10^{-3}$ & 9.163 \\
\hline 285.68 & 0.7240 & $4.0 \times 10^{-3}$ & 9.599 \\
\hline 303.51 & 0.5762 & $3.4 \times 10^{-3}$ & 9.098 \\
\hline
\end{tabular}
d Standard uncertainties in temperature $u(T)=0.08 \mathrm{~K}, u(p) / p=0.036 \%$

At $T=(272$ and 285$) \mathrm{K}$, the differences in the critical points estimated by the two methods were comparable to their combined experimental uncertainties, which were dominated by the statistical uncertainty associated with the extrapolation of the surface tension curve to $\gamma=0$. However, at $T=$ $303 \mathrm{~K}$, the differences in the values obtained by the two methods were significant: 0.039 in overall methane mole fraction and $0.085 \mathrm{MPa}$ in pressure, with the observation of critical opalescence occurring at a much higher pressure and methane fraction than would have been inferred from the extrapolation to $\gamma=0$. Given the results obtained for pure ethane and the difficulties associated with extrapolation, we recommend the values determined via the observation of critical opalescence, and these are listed in Table 9. The critical parameters determined from the extrapolation method are summarised in the Supporting Information. The variation in the critical composition obtained with the two methods ( $0.039 \mathrm{CH}_{4}$ mole fraction) can be interpreted as representing a bound on the possible uncertainty in composition due to fractionation and/or mixing between the propane-rich dead volume below the cell and the liquid mixture near the interface.

The two EOS predict similar conditions for the mixture critical points at the lower temperatures $(272 \mathrm{~K}$ and $285 \mathrm{~K})$. The predicted critical points at these temperatures have significantly lower methane mole fractions of 0.73 and 0.67 at $T=(272$ and 285$) \mathrm{K}$, respectively. At $T=304 \mathrm{~K}$, the two EOS predict quite different mixture critical points, with PRA prediction having $z_{1}$ larger than the GERG-2008 prediction by 0.026 , and the critical pressure larger by $0.34 \mathrm{MPa}$. At this temperature, both predictions are to the right of the critical opalescence condition, with the GERG-2008 EOS prediction being the closest, but nevertheless over-predicting the measurement by 0.0083 and 0.149 MPa.

The measured critical opalescence temperature and pressure are shown in Figure 14 as a function of composition for these binaries. These are directly compared with critical point literature data from Roof and Baron ${ }^{61}$, Sage et al. ${ }^{13}$, Reamer et al. ${ }^{62}$ and Wichterle and Kobayashi ${ }^{63}$ for methane (1) + propane (2) mixtures. The predicted critical temperature and pressure calculated with the GERG2008 and PRA EOS are also shown in Figure 14 as a function of composition from pure propane to pure methane. The present results are generally consistent with the literature data, and add to the data for low temperature and high methane mole fraction previously studied. At $273 \mathrm{~K}$, the predicted critical temperature is significantly lower than suggested by the trend in the measured data. The deviations between the measured critical point at a specified mixture composition from that predicted with the GERG-2008 EOS are shown in Figure 15. The deviations of the literature data and the PRA EOS predictions from GERG-2008 predictions of $\left(T_{c}, p_{c}\right)$ are also shown. At the experimental critical point compositions measured in this work for $T=(272,286$ and 303$) \mathrm{K}$, the deviation from the GERG-2008 EOS in $T_{\mathrm{c}}$ was $+27 \mathrm{~K},+11 \mathrm{~K}$, and $0.49 \mathrm{~K}$, respectively, while for $p_{\mathrm{c}}$ it was $0.046 \mathrm{MPa},-0.33 \mathrm{MPa},-0.17 \mathrm{MPa}$, respectively. 


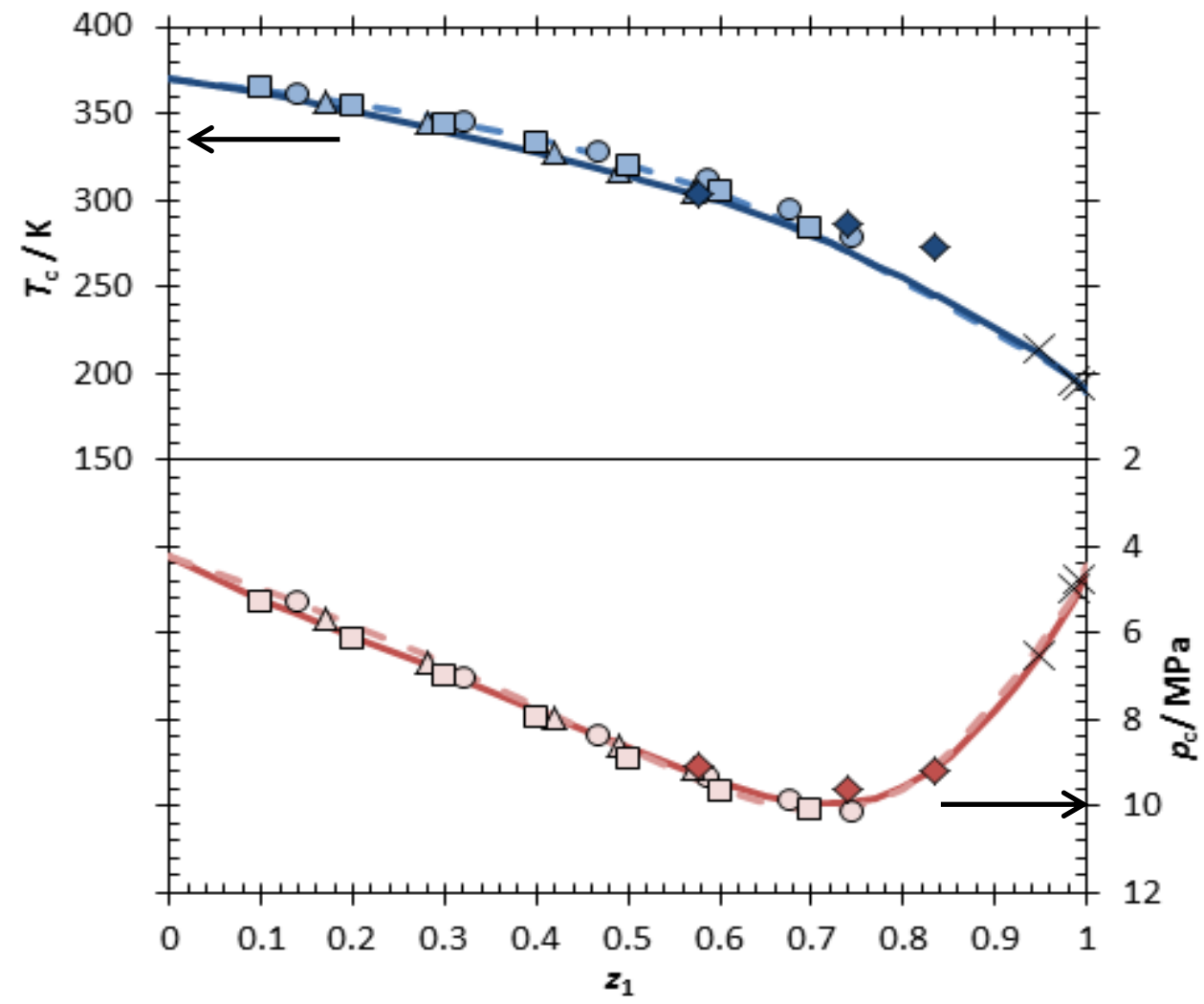

Figure 14: Critical temperature and pressure measurements for methane (1) + propane (2) mixtures as a function of overall methane mole fraction. This work: $\diamond, p_{c}, \diamond, T_{c}$. Literature Data: Roof and Baron ${ }^{61}: \triangle, p_{c}, \triangle, T_{c}$; ; Sage et al. ${ }^{13}: \square, p_{c}, \square, T_{c}$; Reamer et al. ${ }^{62}: \bigcirc, p_{c}, O, T_{c}$; Wichterle and Kobayashi ${ }^{63}: \times, p_{c}, \times, T_{c}$. Predicted mixture critical points: PRA EOS: $-, T_{c},,-, p_{c}$ and GERG2008 EOS: $-\ldots, T_{\mathrm{c}},-, p_{\mathrm{c}}$. 


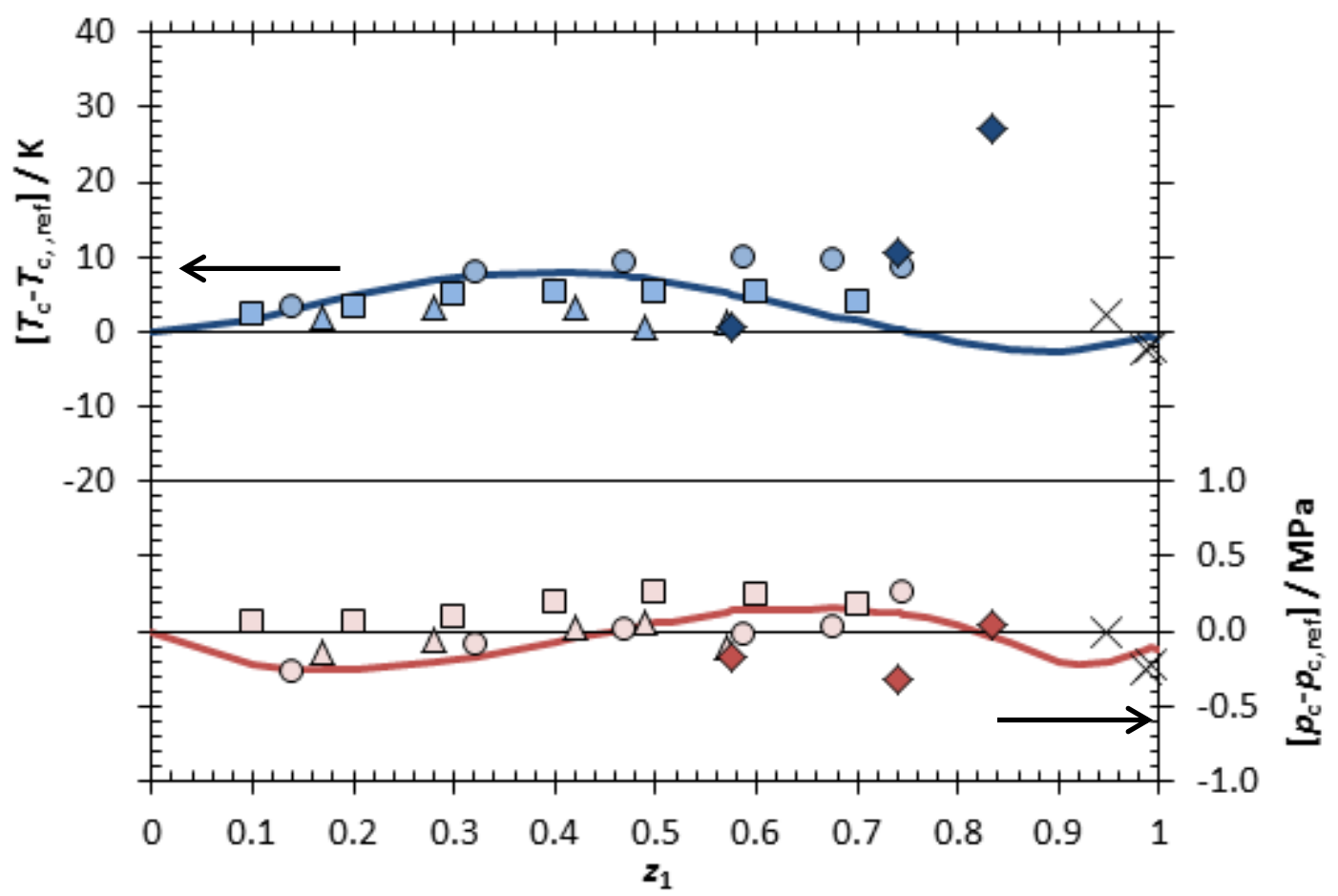

Figure 15: Deviation of critical temperature and pressure from GERG-2008 predictions, $T_{c, \text { ref }}, p_{c, \text { ref }}$ for methane (1) + propane (2) mixtures as a function of overall methane mole fraction. This work: $\diamond, p_{c}$, $\diamond, T_{c}$. Literature Data: Roof and Baron ${ }^{61}: \triangle, p_{c}, \triangle, T_{c}$; Sage et al. ${ }^{13}: \square, p_{c}, \quad \square, T_{c}$; Reamer et al. ${ }^{62}$ :

$\mathrm{O}, p_{c}, \mathrm{O}, T_{c}$, ;Wichterle and Kobayashi ${ }^{63}: \times, p_{c}, \times, T_{c}$. Predicted mixture critical points: PRA EOS:

$$
\longrightarrow, T_{c},-, p_{c} \text {. }
$$

\section{Conclusion}

A differential capillary rise apparatus consisting of a sapphire equilibrium cell was designed and used for measuring the small surface tensions of hydrocarbon mixtures in the vicinity of their critical points. The cell, designed for operation at pressures to $24 \mathrm{MPa}$, contained a re-circulation pump for mixing and two syringe pumps for manipulating the level of the bulk interface as well as changing system composition and pressure. The capillary radii were calibrated using a reference value for saturated propane's surface tension at $T=271 \mathrm{~K}$ and the technique was validated through measurements with saturated ethane. Critical points were measured via the observation of critical opalescence (CO); extrapolation of the measured surface tension to zero provided an independent (although less accurate) estimate of the critical point that agreed reasonably well with the CO observations.

Methane + propane mixture surface tensions were measured along three isotherms $T=(272.23$, 285.51 and 303.34) K. The results were compared with models for surface tension implemented in widely used engineering software. These measurements have shown that the default model in REFPROP 9.1 severely over-predicts the surface tension of hydrocarbon mixtures. It is unclear whether this reflects a limitation in the model of Moldover and Rainwater ${ }^{10}$ for this mixture, or if it is due to an error in the implementation of that model in the REFPROP 9.1 software. This will be a point of investigation in future work. The Parachor method implemented in the software package Multiflash and the beta-version of REFPROP 9.2( $\beta$ ) was able to represent the measured data within its estimated uncertainty, as was an implementation of the Linear Gradient Theory within Multiflash. 
The mixture critical points measured here were consistent with those reported in the literature ${ }^{13 ; 61 ;}$ ${ }^{62 ; 63}$. The value measured at $T=273 \mathrm{~K}$ extends previous determinations for this system adding to the low temperature and high methane mole fraction work by Wichterle and Kobayashi ${ }^{63}$. While the critical point predictions of the GERG-2008 equation of state provide a reasonable representation of the literature data given their scatter in critical temperature of $10 \mathrm{~K}$, the new data deviated from the predicted critical temperatures by between ( 0.5 and 27$) \mathrm{K}$. Deviations from the Advanced Peng Robinson EOS implemented in the Multiflash software package were similar. Future experimental work will investigate the impact of including heptane on the surface tension, bubble-point pressure and the critical point of high-pressure ternary hydrocarbon mixtures and extend measurements to lower temperatures.

\section{Acknowledgements}

This work was funded by the Australian Research Council through LP130101008 and IC150100019, and by the Gas Processors Association through project GPA-102. The authors thank Craig Grimm for fabricating and maintaining the apparatus. The authors would also like to thank Marcia Huber for supplying a beta version of REFPROP 9.2, and Mike Moldover for helpful discussions.

\section{Supporting Information Available}

The Supporting Information includes detailed vapour pressure comparison with literature sources for ethane and propane and critical parameters based on the extrapolation method.

\section{References}

[1] H.N. Nilssen, A.O. Fredheim, O.J. Berg, E. Solbraa, B. Kvamme, Equilibrium phase densities, interfacial tensions for the ethane $+n$-pentane system at $294.15 \mathrm{~K}$; Journal of Chemical and Engineering Data 56 (2011) 2128-2132.

[2] A. Rojey, Natural Gas, Editions Technip, Paris, 1997.

[3] A. Mulero, I. Cachadiña, M.I. Parra, Recommended Correlations for the Surface Tension of Common Fluids; Journal of Physical and Chemical Reference Data 41 (2012) 043105.

[4] J.M. Garrido, A. Mejía, M.M. Piñeiro, F.J. Blas, E.A. Müller, Interfacial tensions of industrial fluids from a molecular-based square gradient theory; AIChE Journal 62 (2016) 1781-1794.

[5] D.B. Macleod, On a relation between the viscosity of a liquid and its coefficient of expansion; Transactions of the Faraday Society 19 (1923) 6-16.

[6] S. Sugden, CXLI.-The influence of the orientation of surface molecules on the surface tension of pure liquids; Journal of the Chemical Society, Transactions 125 (1924) 1167-1177.

[7] A.W. Adamson, Physical chemistry of surfaces, 4th ed. ed., New York : J. Wiley, New York, 1982.

[8] E.A. Guggenheim, The Principle of Corresponding States; The Journal of Chemical Physics 13 (1945) 253-261.

[9] C.F. Weinaug, D.L. Katz, Surface Tensions of Methane-Propane Mixtures; Industrial \& Engineering Chemistry 35 (1943) 239-246.

[10] M.R. Moldover, J.C. Rainwater, Interfacial tension and vapor-liquid equilibria in the critical region of mixtures; The Journal of Chemical Physics 88 (1988) 7772-7780.

[11] Y.-X. Zuo, E.H. Stenby, A Linear Gradient Theory Model for Calculating Interfacial Tensions of Mixtures; Journal of Colloid and Interface Science 182 (1996) 126-132.

[12] M.S. Haniff, A.J. Pearce, Measuring Interfacial Tensions in a Gas-Condensate System With a Laser-Light-Scattering Technique; SPE Reservoir Engineering 5 (1990). 
[13] B.H. Sage, W.N. Lacey, J.G. Schaafsma, Phase Equilibria in Hydrocarbon Systems II. MethanePropane System; Industrial \& Engineering Chemistry 26 (1934) 214-217.

[14] E.F. May, J.Y. Guo, J.H. Oakley, T.J. Hughes, B.F. Graham, K.N. Marsh, S.H. Huang, Reference Quality Vapor-Liquid Equilibrium Data for the Binary Systems Methane + Ethane, + Propane, + Butane, and + 2-Methylpropane, at Temperatures from (203 to 273) K and Pressures to $9 \mathrm{MPa}$; Journal of Chemical \& Engineering Data 60 (2015) 3606-3620.

[15] L. Wilhelmy, Ueber die Abhängigkeit der Capillaritäts-Constanten des Alkohols von Substanz und Gestalt des benetzten festen Körpers; Annalen der Physik 195 (1863) 177-217.

[16] P.L. du Noüy, A NEW APPARATUS FOR MEASURING SURFACE TENSION; The Journal of General Physiology 1 (1919) 521-524.

[17] J.F. Padday, A.R. Pitt, R.M. Pashley, Menisci at a free liquid surface: surface tension from the maximum pull on a rod; Journal of the Chemical Society, Faraday Transactions 1: Physical Chemistry in Condensed Phases 71 (1975) 1919-1931.

[18] H.N. Nilssen, A.O. Fredheim, O.J. Berg, E. Solbraa, B. Kvamme, Equilibrium phase densities, vapor phase compositions, and interfacial tensions for the methane + ethane $+\mathrm{n}$-pentane system at 294.15 K; Journal of Chemical and Engineering Data 56 (2011) 4006-4011.

[19] X. Li, E. Boek, G.C. Maitland, J.P.M. Trusler, Interfacial Tension of (Brines + CO2): (0.864 NaCl $+0.136 \mathrm{KCl}$ ) at Temperatures between (298 and 448) K, Pressures between ( 2 and 50) MPa, and Total Molalities of (1 to 5) mol.kg-1; Journal of Chemical \& Engineering Data 57 (2012) 1078-1088.

[20] J.D. Berry, M.J. Neeson, R.R. Dagastine, D.Y.C. Chan, R.F. Tabor, Measurement of surface and interfacial tension using pendant drop tensiometry; Journal of Colloid and Interface Science 454 (2015) 226-237.

[21] R. Hussain, S.J. Vogt, A. Honari, K.G. Hollingsworth, A.J. Sederman, J. Mitchell, M.L. Johns, Interfacial Tension Measurements Using MRI Drop Shape Analysis; Langmuir 30 (2014) 1566-1572.

[22] K.C. Nadler, J.A. Zollweg, W.B. Streett, I.A. McLure, Surface tension of argon + krypton from 120 to $200 \mathrm{~K}$; Journal of Colloid and Interface Science 122 (1988) 530-536.

[23] V.N. Andbaeva, M.N. Khotienkova, Experimental study of surface tension of ethane-methane solution in temperature range 213-283 K; Thermophys. Aeromech. 20 (2013) 385-389.

[24] V.G. Baidakov, A.M. Kaverin, M.N. Khotienkova, Surface tension of ethane-methane solutions: 1. Experiment and thermodynamic analysis of the results; Fluid Phase Equilibria 356 (2013) 90-95.

[25] V.G. Baidakov, A.M. Kaverin, M.N. Khotienkova, V.N. Andbaeva, Surface tension of an ethane-nitrogen solution. 1: Experiment and thermodynamic analysis of the results; Fluid Phase Equilibria 328 (2012) 13-20.

[26] V.G. Baidakov, M.N. Khotienkova, V.N. Andbaeva, A.M. Kaverin, Capillary constant and surface tension of methane-nitrogen solutions: 1. Experiment; Fluid Phase Equilibria 301 (2011) 6772.

[27] V.G. Baidakov, I.I. Sulla, Surface tension of helium-oxygen and helium-ethane solutions; International Journal of Thermophysics 16 (1995) 909-927.

[28] Y. Nishimura, A. Hasegawa, Y. Nagasaka, High-precision instrument for measuring the surface tension, viscosity and surface viscoelasticity of liquids using ripplon surface laser-light scattering with tunable wavelength selection; Review of Scientific Instruments 85 (2014) 044904.

[29] A.J. Pearce, M.S. Haniff, Light-scattering experiments from a carbon dioxide surface near the critical point; Journal of Colloid and Interface Science 119 (1987) 315-325.

[30] L.L. Handy, M. El-Gassier, I. Ershaghi, A Modified Spinning Drop Method for HighTemperature Applications; Society of Petroleum Engineers Journal 23 (1983).

[31] M.S. Haniff, A.J. Pearce, Measuring Interfacial Tensions in a Gas-Condensate System With a Laser-Light-Scattering Technique; (1990).

[32] J. Drelich, C. Fang, C. White, Measurement of interfacial tension in fluid-fluid systems; Encyclopedia of Surface and Colloid Science (2002) 3152-3166.

[33] M.J. Neeson, D.Y.C. Chan, R.F. Tabor, Compound Pendant Drop Tensiometry for Interfacial Tension Measurement at Zero Bond Number; Langmuir 30 (2014) 15388-15391. 
[34] A. Hyde, C. Phan, G. Ingram, Determining liquid-liquid interfacial tension from a submerged meniscus; Colloids and Surfaces A: Physicochemical and Engineering Aspects 459 (2014) 267-273.

[35] S. Sugden, CLXXV.-The determination of surface tension from the rise in capillary tubes; Journal of the Chemical Society, Transactions 119 (1921) 1483-1492.

[36] E.W. Lemmon, Huber, M.L, McLinden, M.O, NIST STandard Reference Database 23: Reference Fluid Thermodynamic and Transport Properties - REFPROP, Version 9.1; (2013).

[37] M. Huber, Private Communication. in: K. Marsh, (Ed.), November, 2015.

[38] A.S. Negi, S.C. Anand, A Textbook of Physical Chemistry, Wiley Eastern, 1985.

[39] I.K.A.T. PLC, Multiflash 4.4 - User Guide for Models and Physical Properties, 2014.

[40] E.B. Poling, J.M. Prausnitz, J.P. O'Connell, The properties of gases and liquids, McGraw-Hill, New York, 2001.

[41] S.-T. Lee, M.C.H. Chien, A New Multicomponent Surface Tension Correlation Based on Scaling Theory, Society of Petroleum Engineers, 1984.

[42] K.S. Pedersen, Properties of oils and natural gases, Houston : Gulf Pub. Co., Book Division, Houston, 1989.

[43] Y.-X. Zuo, E.H. Stenby, Calculation of interfacial tensions with gradient theory; Fluid Phase Equilibria 132 (1997) 139-158.

[44] L. Rayleigh, On the Theory of the Capillary Tube; Proceedings of the Royal Society of London A: Mathematical, Physical and Engineering Sciences 92 (1916) 184-195.

[45] M.R. Moldover, J.W. Cahn, An Interface Phase Transition: Complete to Partial Wetting; Science 207 (1980) 1073-1075.

[46] J.E. Lane, Correction terms for calculating surface tension from capillary rise; Journal of Colloid And Interface Science 42 (1973) 145-149.

[47] T.W. Richards, E.K. Carver, A Critical Study Of The Capillary Rise Method Of Determining Surface Tension, With Data For Water, Benzene, Toluene, Chloroform, Carbon Tetrachloride, Ether And Dimethyl Aniline. ; Journal of the American Chemical Society 43 (1921) 827-847.

[48] O. Kunz, W. Wagner, The GERG-2008 Wide-Range Equation of State for Natural Gases and Other Mixtures: An Expansion of GERG-2004; Journal of Chemical \& Engineering Data 57 (2012) 3032-3091.

[49] O. Kunz, Klimeck, R., Wagner, W., Jaeschke, M, The GERG-2004 wide-range equation of state for natural gases and other mixtures. ; GERG TM15 (2007).

[50] Rayotek Scientific Inc., 2014, https://www.rayotek.com

[51] Friedrich \& Dimmock, Inc., 2014, http://www.fdglass.com/

[52] E.W. Lemmon, M.O. McLinden, W. Wagner, Thermodynamic Properties of Propane. III. A Reference Equation of State for Temperatures from the Melting Line to $650 \mathrm{~K}$ and Pressures up to $1000 \mathrm{MPa}$; Journal of Chemical \& Engineering Data 54 (2009) 3141-3180.

[53] U. Setzmann, W. Wagner, A New Equation of State and Tables of Thermodynamic Properties for Methane Covering the Range from the Melting Line to $625 \mathrm{~K}$ at Pressures up to $100 \mathrm{MPa}$; Journal of Physical and Chemical Reference Data 20 (1991) 1061-1155.

[54] D. Bücker, W. Wagner, A Reference Equation of State for the Thermodynamic Properties of Ethane for Temperatures from the Melting Line to $675 \mathrm{~K}$ and Pressures up to $900 \mathrm{MPa}$; Journal of Physical and Chemical Reference Data 35 (2006) 205-266.

[55] J.J. Hurly, J.W. Schmidt, S.J. Boyes, M.R. Moldover, Virial equation of state of helium, xenon, and helium-xenon mixtures from speed-of-sound and burnettP $\rho$ T measurements; International Journal of Thermophysics 18 (1997) 579-634.

[56] J. Jurin, An Account of Some Experiments Shown before the Royal Society; With an Enquiry into the Cause of the Ascent and Suspension of Water in Capillary Tubes. ; Philosophical Transactions 30 (1717) 739-747.

[57] N. Bouras, M.A. Madjoubi, M. Kolli, S. Benterki, M. Hamidouche, Thermal and mechanical characterization of borosilicate glass; Physics Procedia 2 (2009) 1135-1140.

[58] D.L. Katz, W. Saltman, Surface Tension of Hydrocarbons; Industrial \& Engineering Chemistry 31 (1939) 91-94. 
[59] H. Lin, Y.-Y. Duan, Surface Tension Measurements of Propane (R-290) and Isobutane (R600a) from (253 to 333) K; Journal of Chemical \& Engineering Data 48 (2003) 1360-1363.

[60] M. Funke, R. Kleinrahm, W. Wagner, Measurement and correlation of the $(p, \rho, T)$ relation of ethane II. Saturated-liquid and saturated-vapour densities and vapour pressures along the entire coexistence curve; The Journal of Chemical Thermodynamics 34 (2002) 2017-2039.

[61] J.G. Roof, J.D. Baron, Critical loci of binary mixtures of propane with methane, carbon dioxide, and nitrogen; Journal of Chemical \& Engineering Data 12 (1967) 292-293.

[62] H.H. Reamer, B.H. Sage, W.N. Lacey, Phase Equilibria in Hydrocarbon Systems. Volumetric and Phase Behavior of the Methane-Propane System; Industrial \& Engineering Chemistry 42 (1950) 534-539.

[63] I. Wichterle, R. Kobayashi, Vapor-liquid equilibrium of methane-propane system at low temperatures and high pressures; Journal of Chemical \& Engineering Data 17 (1972) 4-9. 